International Journal of Automotive and Mechanical Engineering ISSN: 2229-8649 (Print); ISSN: 2180-1606 (Online)

Volume 15, Issue 2 pp. 5326-5346 June 2018

(C) Universiti Malaysia Pahang, Malaysia

DOI: https://doi.org/10.15282/ijame.15.2.2018.13.0410

\title{
Numerical Study of Suction and Blowing Approaches to Control Flow over a Compressor Cascade in Turbulent Flow Regime
}

\author{
H. Fatahian ${ }^{\text {1* }}$, H. Salarian ${ }^{2}$, M. Eshagh Nimvari ${ }^{3}$ and E. Fatahian ${ }^{1}$ \\ ${ }^{1}$ Young Researchers and Elite Club, Nour Branch, Islamic Azad University, Nour, Iran \\ ${ }^{2}$ Department of Mechanical Engineering, Nour branch, Islamic Azad University, \\ Nour, Iran \\ ${ }^{3}$ Faculty of Engineering, Amol University of Special Modern Technologies, Amol, Iran \\ *Email: fatahianhossein@gmail.com
}

\begin{abstract}
In the present study, a numerical simulation of turbulent flow over the NACA 65-100 compressor cascade was conducted to control the boundary layer using both suction and blowing separately. In order to study the effects of suction and blowing over the blade, 10 slots were considered on the upper surface of the blade. The slots were considered at intervals of 5\% to $95 \%$ of the blade chord length. The results showed that applying both suction and blowing caused to delay the flow separation point and move it downstream which led to increase the lift coefficient and decrease the drag coefficient. Also, it was concluded that the effect of applying suction especially in the location where is near the trailing edge was significantly more than the effect of applying blowing. So that the lift coefficient had increased about $45 \%$ at $95 \%$ of chord length for suction compared to 5\% of chord length and it had increased about $10 \%$ at $95 \%$ of chord length for blowing compared to 5\% of chord length. Moreover, the best location to apply suction and blowing in a compressor cascade was near the flow separation point where is near the trailing edge.
\end{abstract}

Keywords: Compressor cascade; boundary layer; suction and blowing; lift and drag coefficients; flow separation.

\section{INTRODUCTION}

Generally, flow separation increased energy losses and operating instability, so flow separation control is required for improving aerodynamic performance. In the published studies, methods of flow separation control have been presented [1]. The significant effect of boundary layer suction for improving the aerodynamic performance has already been revealed since 1971 [2]. In 1997, the conception of aspirated compressors stated by Kerrebrock et al. [3-4]. Schuler et al. [5] experimentally studied the transonic aspirated stage that representing the use of boundary layer aspiration in order to increase the stage work. The experimental results were compared to the CFD calculation and discussed in detail. Moreover, suction and aspiration were applied interchangeably in their study. In the study of Fottner [6], a semi-empirical calculation method was developed in highly-loaded compressor cascades to design the blowing configuration. He indicated that if the injected flow has enough energy for eliminating the boundary layer separation completely, the cascade operating range could be significantly increased. In the study of Merchant [7], two aspirated compressor stages were designed and exit guide vane of aspirated turbine was studied. He investigated the effect of suction method on the airfoils aerodynamic. 
Qiang et al. [8] and Wang et al. [9] presented a new design concept of highly loaded axial flow compressor that applies 3D blade technique and suction. Their results indicated that boundary layer suction was applied for decreasing the separation loss due to the significantly increase of the turning angle of the stator. The influences of suction flow rates and suction positions on the losses and the flow deviation at cascade exits were experimentally studied by Niu et al. [10]. Their results demonstrated that the advantageous of suction method are very limited due to the suction flow rates and small profile camber angle which they applied in their calculation. Zheng et al. [11] investigated the periodic suction and blowing over the axial compressor cascades. They revealed that these methods could control the disordered unsteady separate flows and also improve effectively the aerodynamic performances of the axial compressor cascades.

In the Harbin Institute of Technology, Song et al. [12-14] and Chen et al. [1517] numerically studied the effect of suction method on the aerodynamic performance of a compressor cascade with a large camber angle. Their results indicated that the suction method has a great impact in order to enhance the compressor cascade performance. Nerger et al. [18] experimentally investigated active flow control using endwall and suction side blowing over linear stator cascade. They applied significant suction side boundary layer separation and secondary flow at baseline conditions without blowing. Consequently, in order to decrease the total pressure loss for some of the operating points, flow blowing was more effective. Guo et al. [19] experimentally studied the effects of suction method on the vortex structure of compressor cascade. The possibility of applying the suction method was also investigated in their study. Ding et al. [20] experimentally and numerically studied the use of boundary layer suction holes over a compressor cascade. They found that both side and middle suctions on the suction surface can significantly remove low-energy fluid for improving the cascade load capacity.

Sarimurat et al. [21] applied the steady blowing method for controlling the flow over a low-speed compressor based on both CFD method and integral method. In their study, both theory and CFD results indicated that the change in trailing edge momentum thickness is a function of the change in the momentum thickness across the blowing location. In this study, the numerical simulation and comparison of suction and blowing approaches were conducted separately to control the boundary layer flow around the NACA 65-100 compressor cascade in the turbulent flow regime. Also, the effect of slot location for both suction and blowing on the flow pattern and turbulence characteristics was studied.

\section{GEOMETRY OF COMPRESSOR CASCADE}

Figure 1 shows the geometry of compressor cascade with the coordinate axes. The computational domain consists of a channel with the length of 0.25 meters, the inlet of 0.2 meters and the outlet of 0.2 meters. The chord length of the blades was 0.08 meters and the blades had located with the angle of $\alpha$ equal to $17^{\circ}$. The interval between the blades was 0.04 meters and the blades had located in 0.06 meters from the inlet of channel [22]. 


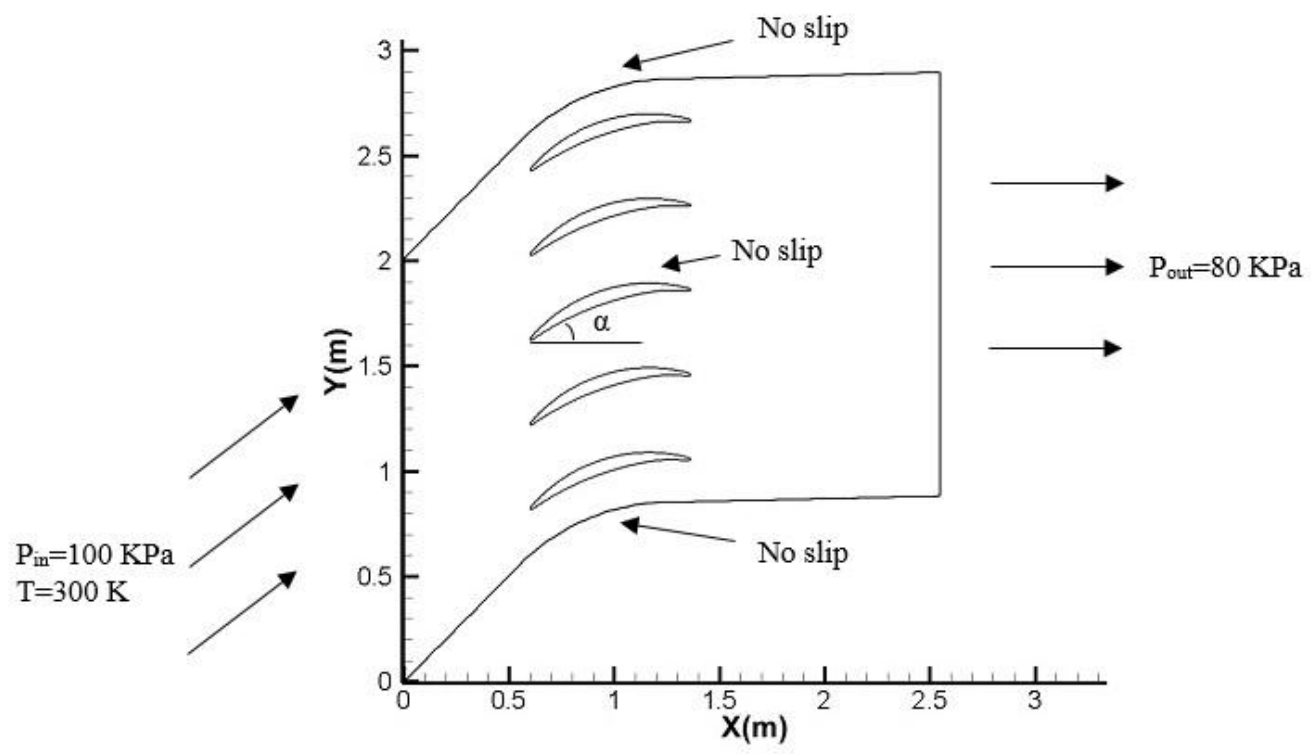

Figure 1. Geometry of compressor cascade, boundary conditions and coordinate axes

In the present study, 10 slots for applying suction and blowing were considered separately with interval of $10 \%$ of the blade chord length was between $5 \%$ to $95 \%$ of the blade chord length. Each slot with a width of $2.5 \%$ of the blade chord length was located respectively in the intervals of $5 \%, 15 \%, 25 \%, 35 \%, 45 \%, 55 \%, 65 \%, 75 \%$, $85 \%$ and $95 \%$ of the blade chord length from the leading edge.

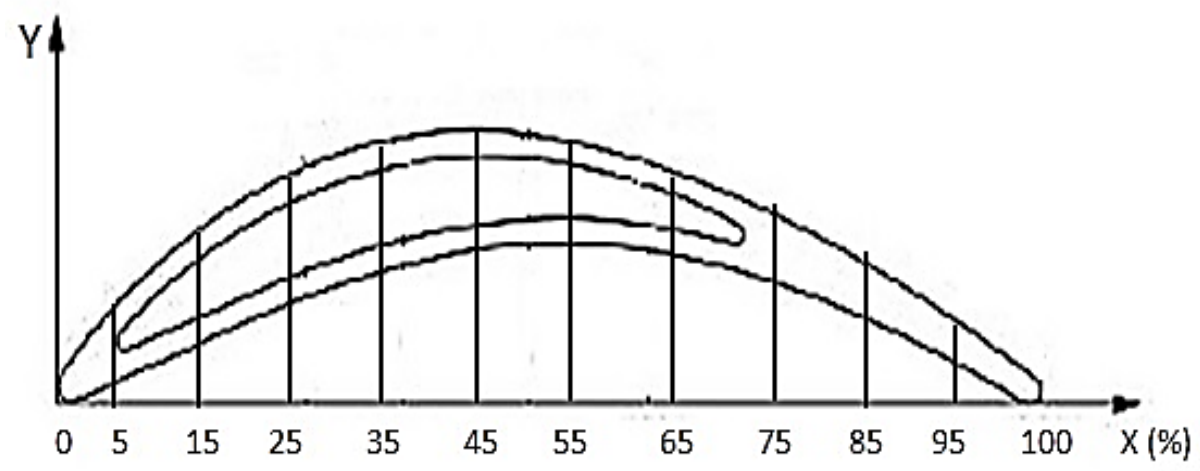

Figure 2. Slots location on the blade chord length from the leading edge

\section{NUMERICAL METHOD}

\section{The Governing Equations and Boundary Conditions}

The flow over compressor cascade was considered as two-dimensional. The problem was considered as isothermal and heat transfer was neglected. The air as a working fluid was considered to be ideal gas. SST k- $\omega$ turbulence model has been proven to perform well in simulation of the attached flow of the airfoil [23] so this turbulence model had been used in this study. The flow was considered as steady state and it was assumed to be a Newtonian fluid. Governing mass and momentum equations can be written as in Eq. (1) and (2): 
$\frac{\partial \rho}{\partial t}+\nabla \cdot(\rho \vec{V})=0$

$\frac{\partial}{\partial t}(\rho \vec{V})+\nabla \cdot(\rho \vec{V} \vec{V})=-\nabla P+\nabla(\overline{\bar{\tau}})$

Where $\mathrm{v}$ is velocity, $\rho$ is density, $\mathrm{P}$ is pressure and $\tau$ is shear stress. The transport equations for SST k- $\omega$ model are given by Eq. (3) and (4):

$$
\begin{aligned}
& \frac{\partial}{\partial t}(\rho k)+\frac{\partial}{\partial x_{i}}\left(\rho k v_{i}\right)=\frac{\partial}{\partial x_{j}}\left(\Gamma k \frac{\partial k}{\partial x_{j}}\right)+G_{k}-Y_{k}+S_{k} \\
& \frac{\partial}{\partial t}(\rho \omega)+\frac{\partial}{\partial x_{i}}\left(\rho \omega v_{i}\right)=\frac{\partial}{\partial x_{j}}\left(\Gamma \omega \frac{\partial \omega}{\partial x_{j}}\right)+G_{\omega}-Y_{\omega}+D_{\omega}+S_{\omega}
\end{aligned}
$$

where $G_{k}$ demonstrates the generation of turbulent kinetic energy due to the mean velocity gradients; $G_{\omega}$ represents the generation of $\omega ; \Gamma_{k}$ indicates the effective diffusivity of $k ; \Gamma_{\omega}$ shows the effective diffusivity of $\omega ; Y_{k}$ and $Y_{\omega}$, respectively indicates the dissipation of $\mathrm{K}$ and $\omega$ due to turbulence; $\mathrm{D}_{\omega}$ represents the cross-diffusion term; $S_{k}$ and $S_{\omega}$ are user-defined source terms [24].

According to the study of Turek [22], it was assumed that inlet flow has a Mach number of 0.6 and inlet pressure of $100 \mathrm{KPa}$. In order to determine the quantities of turbulence, inlet turbulence intensity was considered equal to $5 \%$. The outlet pressure was considered for outlet boundary condition equal to $80 \mathrm{KPa}$ and No-slip wall boundary condition was considered for the upper and lower walls and also the boundary of the blades. Furthermore, total temperature was $300 \mathrm{~K}$. Equations were discretized by finite volume method. Terms of the flow, turbulence kinetic energy and specific dissipation rate were discretized by upstream second-order method in the equations. The density-based and implicit methods were applied for solving the equations due to the fluid compressibility assumption. In addition, Roe-FDS scheme was used for the convective flux types. Also, the convergence criterion was considered equal to $10^{-6}$ for decreasing different residuals variables such as the flow, turbulence kinetic energy and specific dissipation rate. Under-Relaxation Factors were considered equal to 0.5 for turbulence kinetic energy, specific dissipation rate and turbulence viscosity.

\section{Grid Independency Study}

In the present study, the grid generation was conducted by using GAMBIT and structured triangular grids were used for inlet and outlet of the computational domain and also between the cascade blades. Figure 3 shows the complete grid view and the boundary layer grid near the blade surface and Figures 4 (a) and 4 (b) illustrates the closer view of the grid around the blade and trailing edge of the blade. 


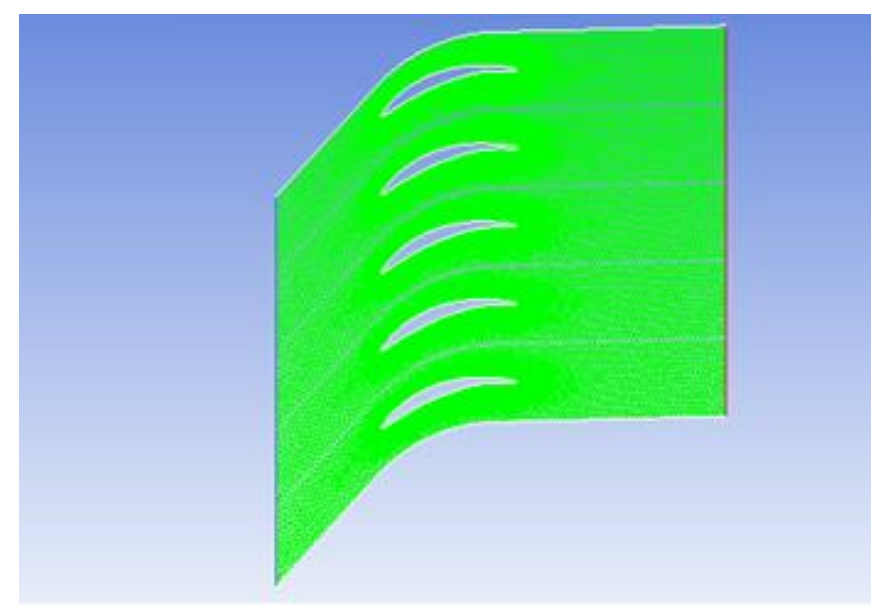

Figure 3. View of entire grid

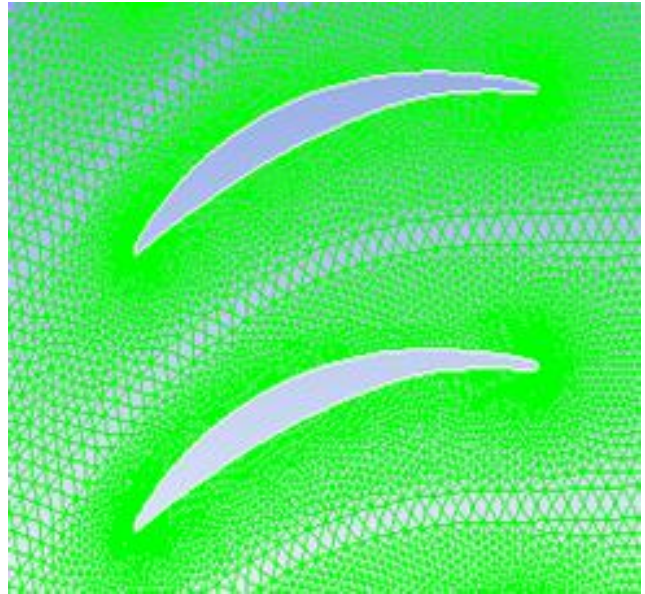

(a)

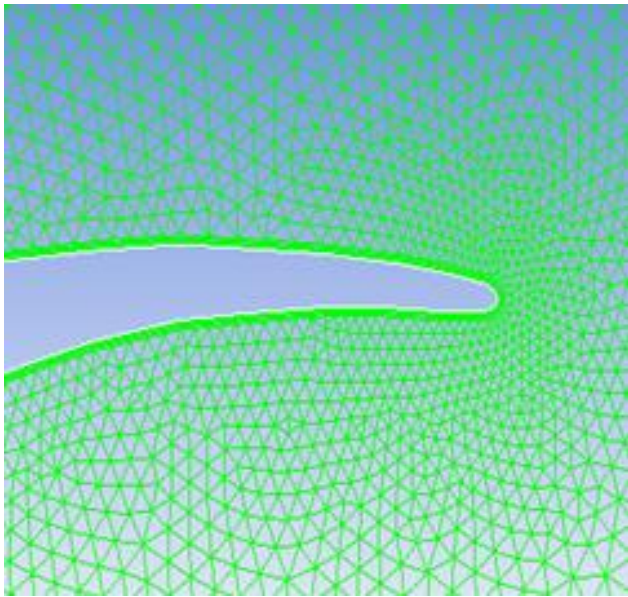

(b)

Figure 4. A closer view of grid around (a) the blade and; (b) trailing edge of the blade.

The results of grid independency for pressure coefficient of upper and lower walls of the blade are shown in Figures 5 (a) and 5 (b). The meshes for different grids were 17820, 54824, 73480, 92170 and 127330, respectively. The results indicated that the difference between the results was negligible and it was about $0.5 \%$ for grid with meshes more than 92170. Therefore, the grid with the number of 92170 meshes was used for all cases.

\section{$\mathbf{Y}^{+}$Distribution around the Blade}

The normal dimensionless distance to the wall is $\mathrm{Y}^{+}[25]$. The value of $\mathrm{Y}^{+}$is an important parameter to achieve the valid results around the solid boundaries. Figure 6 demonstrates the distribution of $\mathrm{Y}^{+}$around the cascade blade. Since $\mathrm{Y}^{+}$has the desired value in the most points around the cascade blade, the local maximum points will not affect the results which can be seen in Figure 6 . In this study, the value of $\mathrm{Y}^{+}$was between 15 and 280 which was at permissible range due to the geometry of compressor cascade, velocity and turbulence model. 


\section{Validation}

In order to verify the simulation results, shear stress on the lower wall of the cascade blade of the present study is compared with the results of Turek [22] in the case of without suction and blowing. Figure 7 shows the changes of shear stress on the lower wall of the cascade blade. As can be seen, the results had a good agreement with the results of Turek [22] so that the maximum difference was about $3 \%$.

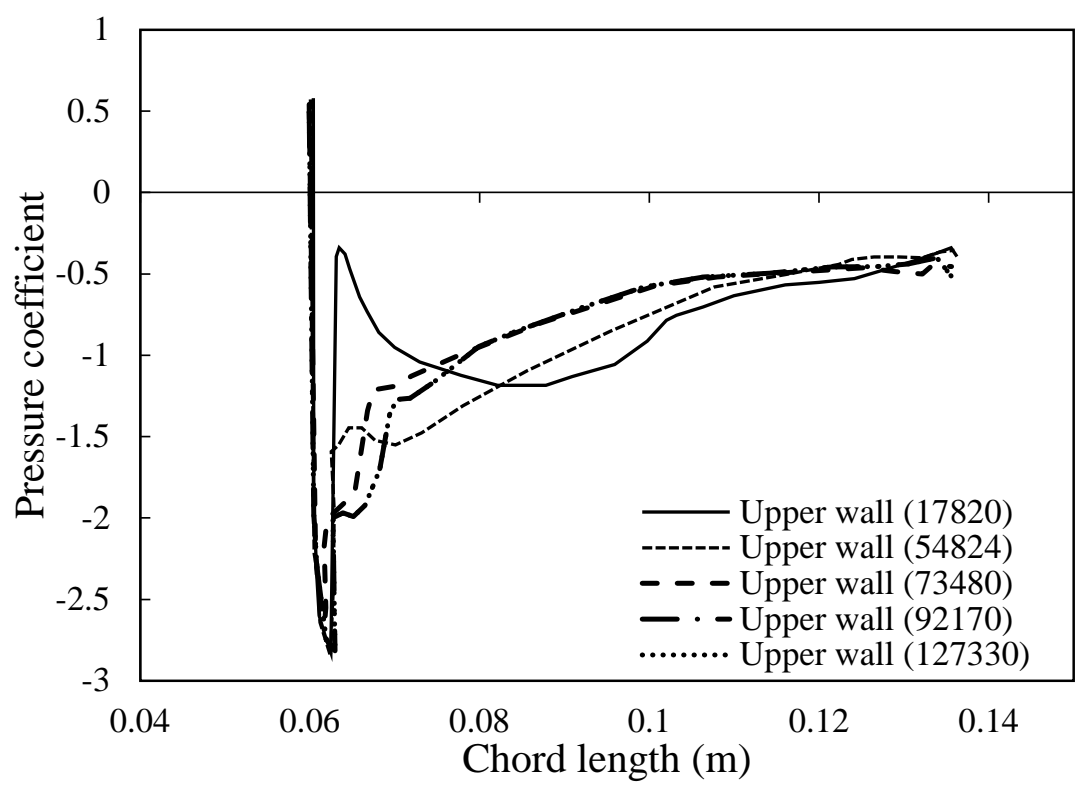

(a)

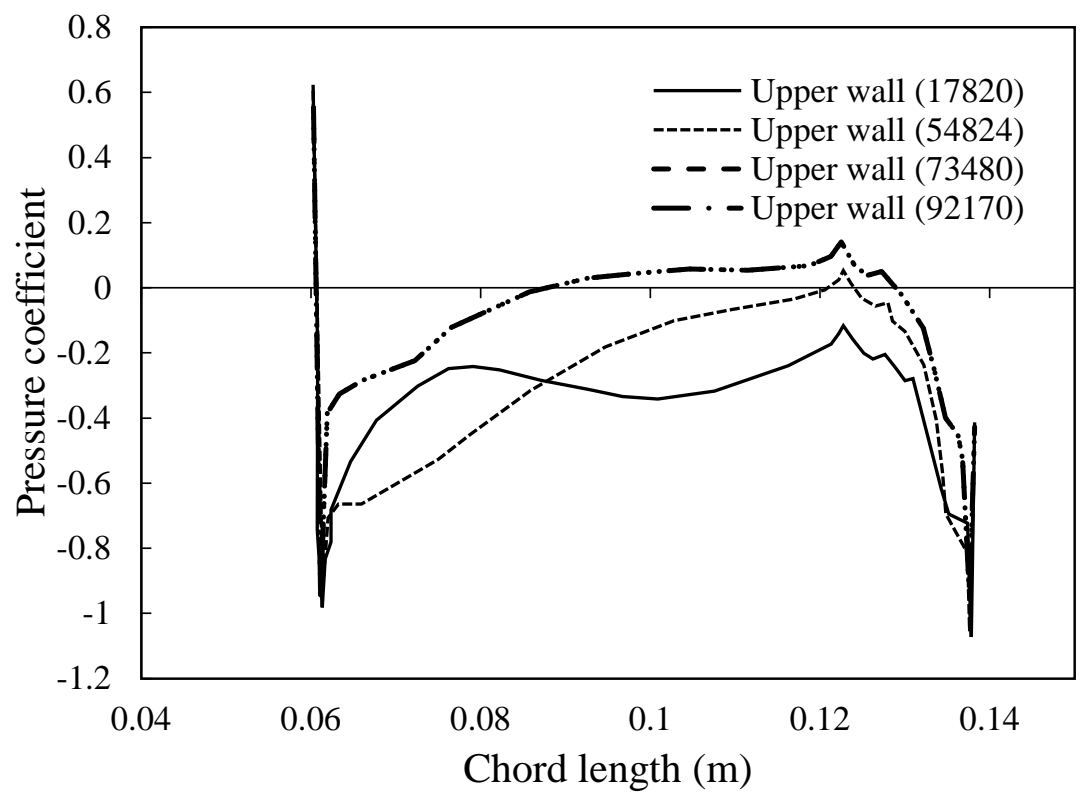

(b)

Figure 5. Changes of pressure coefficient on the (a) upper and (b) lower walls of the blade. 


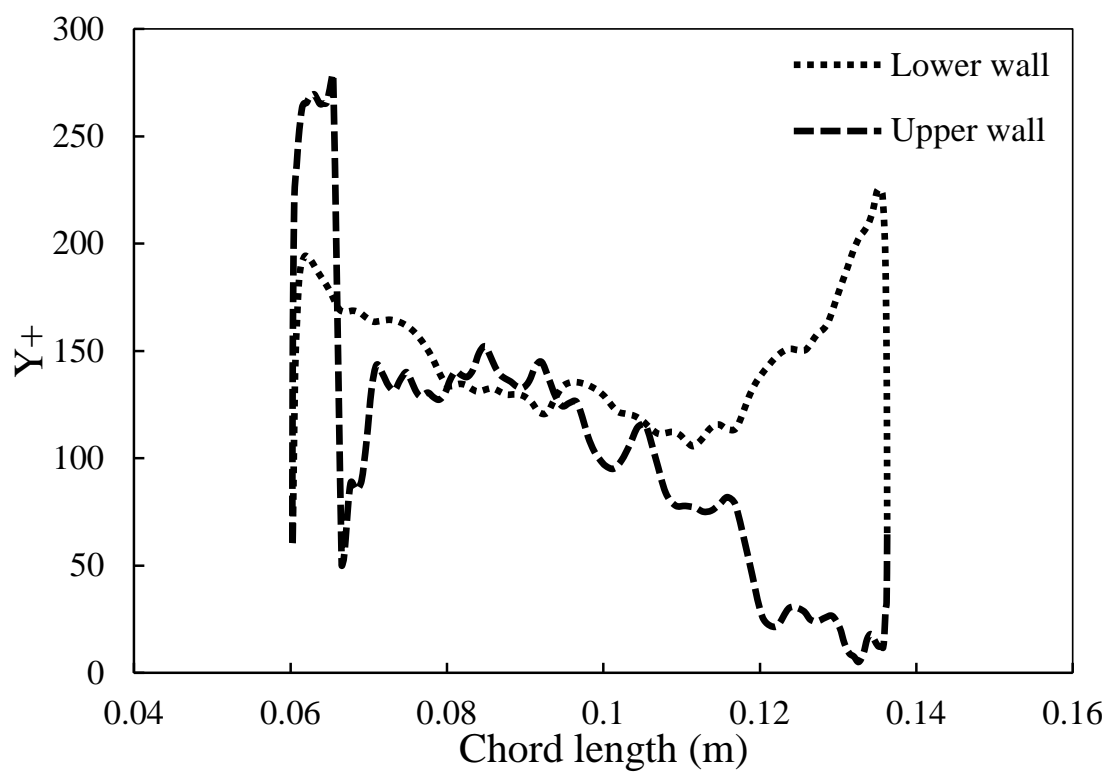

Figure 6. Distribution of $\mathrm{Y}^{+}$around the cascade blade for upper and lower walls.

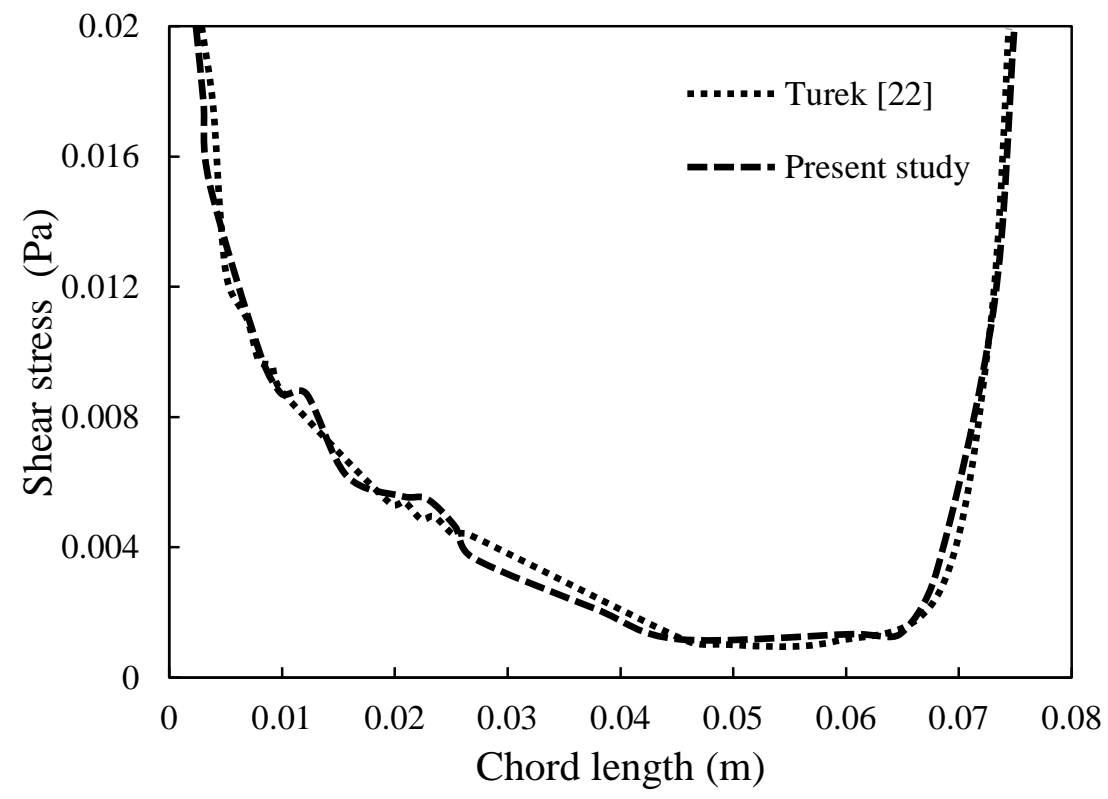

Figure 7. Comparison of shear stress from results of present study and Turek [22].

\section{RESULTS AND DISCUSSION}

\section{Distribution of Mach number over the Cascade Blade}

In Figure 8 (a) to (d) and Figure 9 (a) to (d), Mach number distribution, the movement of shocks is shown based on different slot location for suction and blowing cases. Due to the effect of flow over the cascade blades, an inclined shock to the pressure surface and a perpendicular shock were created in the middle of the blade suction surface. The inclined shock was reflected on the lower blade and the interaction of boundary layer 
shock led to create a separation zone near the trailing edge. In fact, the effect of adverse pressure gradient and boundary layer shock interaction led to create a separation zone near the trailing edge. Also, the effect of inclined shock on boundary layer of the blade led to create marginally separation zone on the pressure side of the blade. In this zone, positive pressure gradient did not allow to induce a severe separation. Unlike the perpendicular shock which was static, the inclined shock moved toward the leading edge and at the same time by approaching the free flow, its intensity decreased and gradually disappeared. The slot location had a great impact on the performance of the compressor cascade [1]. As can be seen, when the suction slot was located at 5\% of the blade chord length, flow separation occurred at $60 \%$ of the blade chord length which influenced by moving the slot to the middle locations and locating suction slot at $45 \%$ of the blade chord length caused to improve the suction performance about $25 \%$.

Previous researches indicated that for compressor cascade, the best location to apply boundary layer suction was near the flow separation point [26]. Because the separation point was near the trailing edge, in this study it was concluded that applying suction at locations near the trailing edge was more effective and caused the separation bubble to move downstream. Finally, the separation bubble completely eliminated where the suction slot was located at $95 \%$ of the blade chord length. In contrast, applying blowing had less effect to control the flow but this did not mean that blowing was not useful for controlling the flow. The stress generated between the layers of the fluid was due to the difference of velocity between these layers. Blowing with suitable conditions, by decreasing this difference of velocity led to has less shear stress and therefore less drag applied to the blade. Applying blowing in middle of the blade chord length had less effect and flow separation had delayed but not completely eliminated by locating the slot at the end locations of the blade chord length, especially at $95 \%$ of the blade chord length.

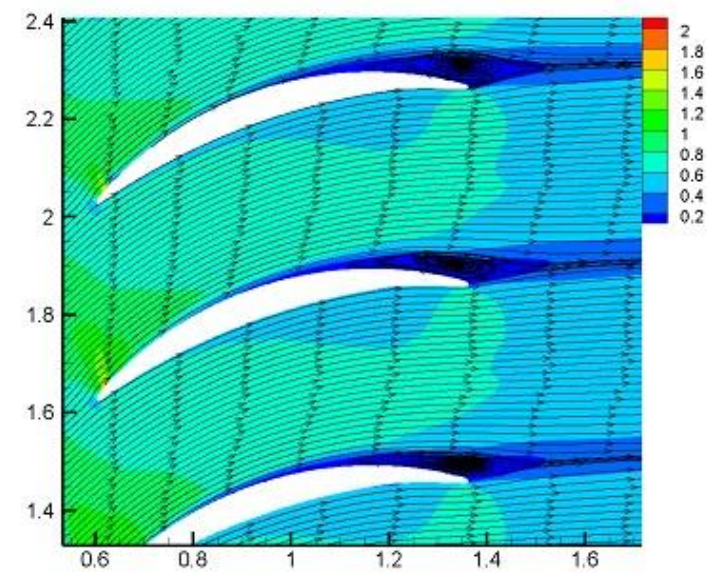

(a)

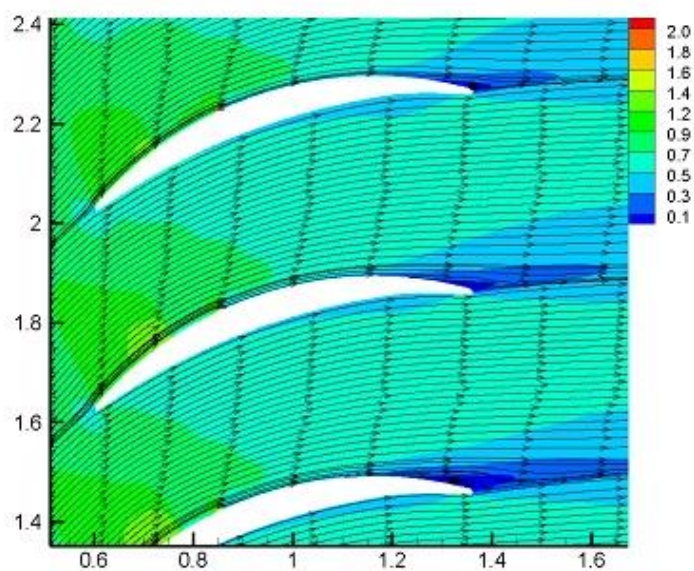

(b) 


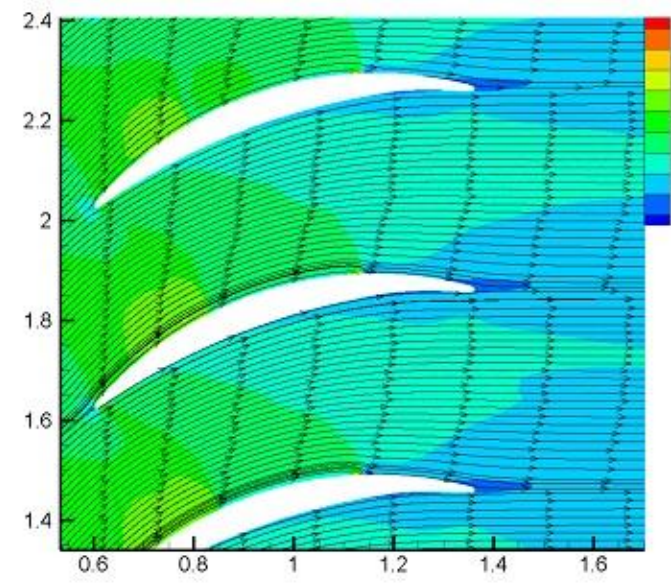

(c)

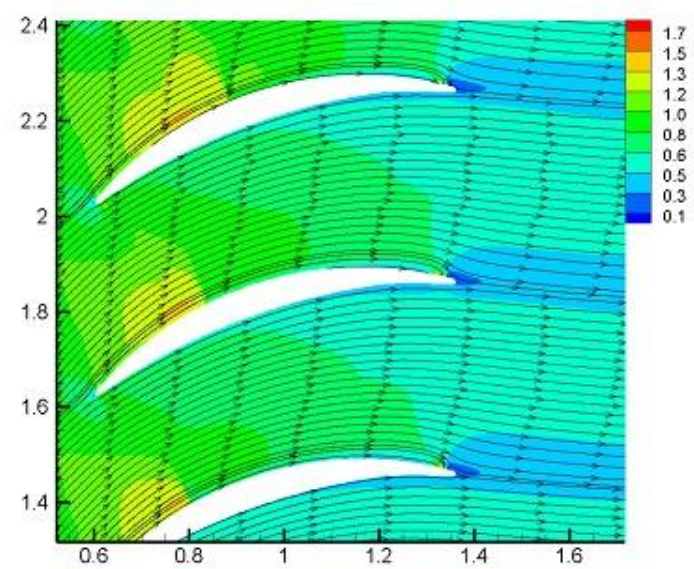

(d)

Figure 8. Mach number distribution of suction case at (a) $5 \%$ (b) $45 \%$ (c) $75 \%$ and (d) $95 \%$ of chord length slot locations.

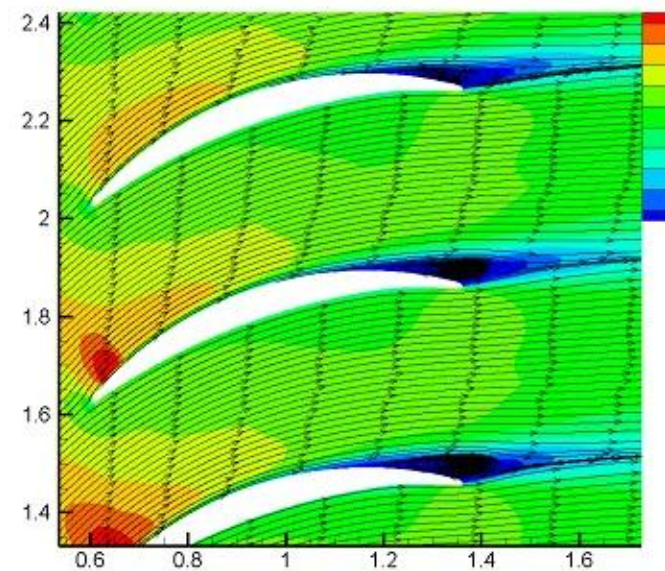

(a)

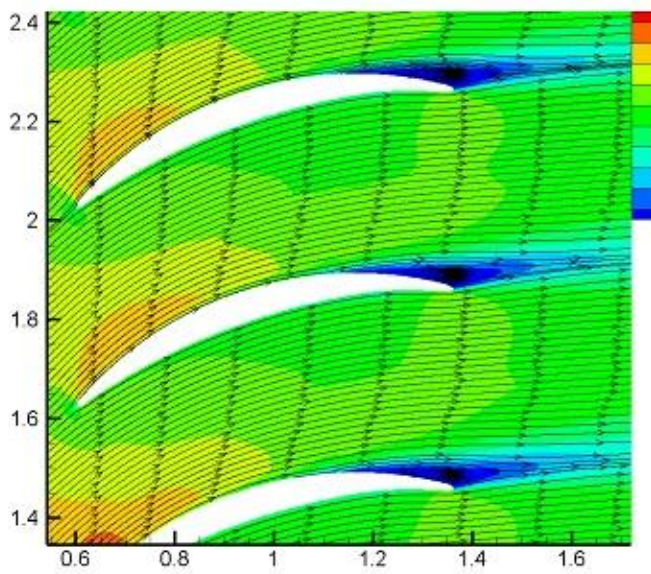

(c)

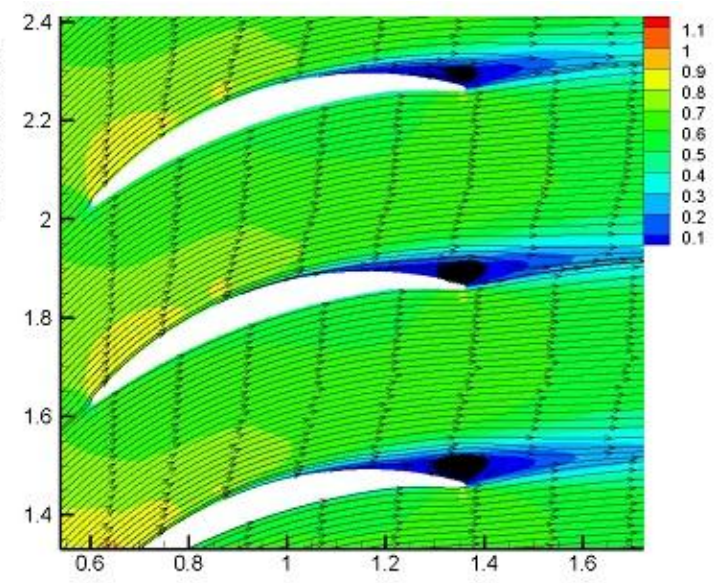

(b)

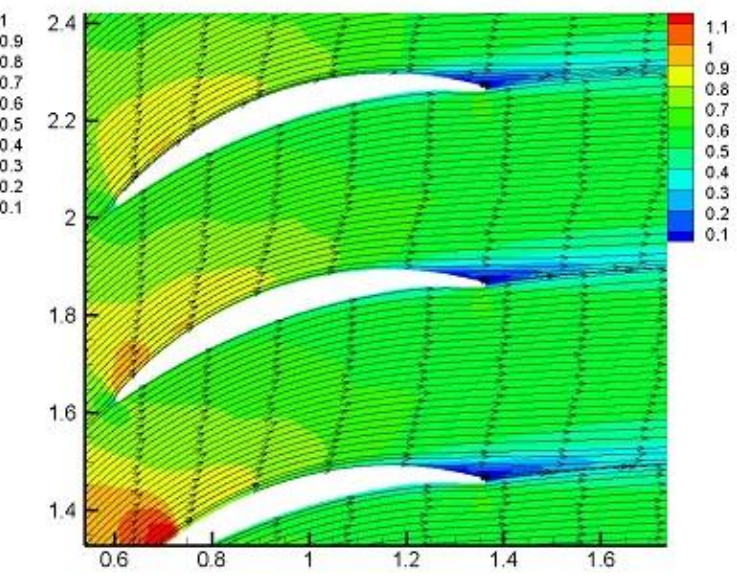

(d)

Figure 9. Mach number distribution of blowing case at (a) $5 \%$ (b) $45 \%$ (c) $75 \%$ and (d) $95 \%$ of chord length slot locations. 


\section{Changes of Mach number on the Blade}

Figure 10 (a) to (c) and Figure 11 (a) to (c) illustrate the changes of calculated Mach number on the upper and lower walls of the blade and for three different cases where the slot was located at 5\%,45\% and 95\% of the blade chord length for suction and blowing cases, respectively. Sudden changes of Mach number can be seen on the upper wall of the blade which caused to make the maximum point due to the shock by effect of applying suction and blowing. But changes of Mach number for lower wall of the blade were quite similar for all cases. Also, it was clear that Mach number was significantly more than other locations of the blade at leading edge of the blade.

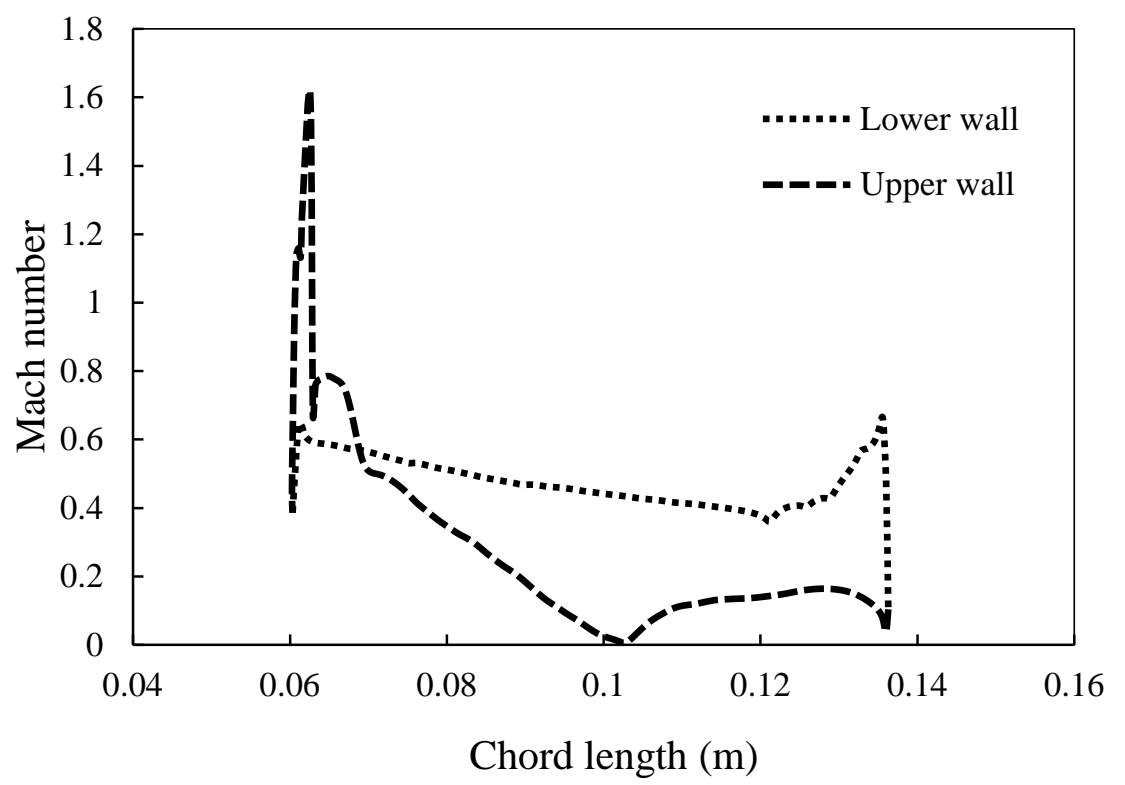

(a)

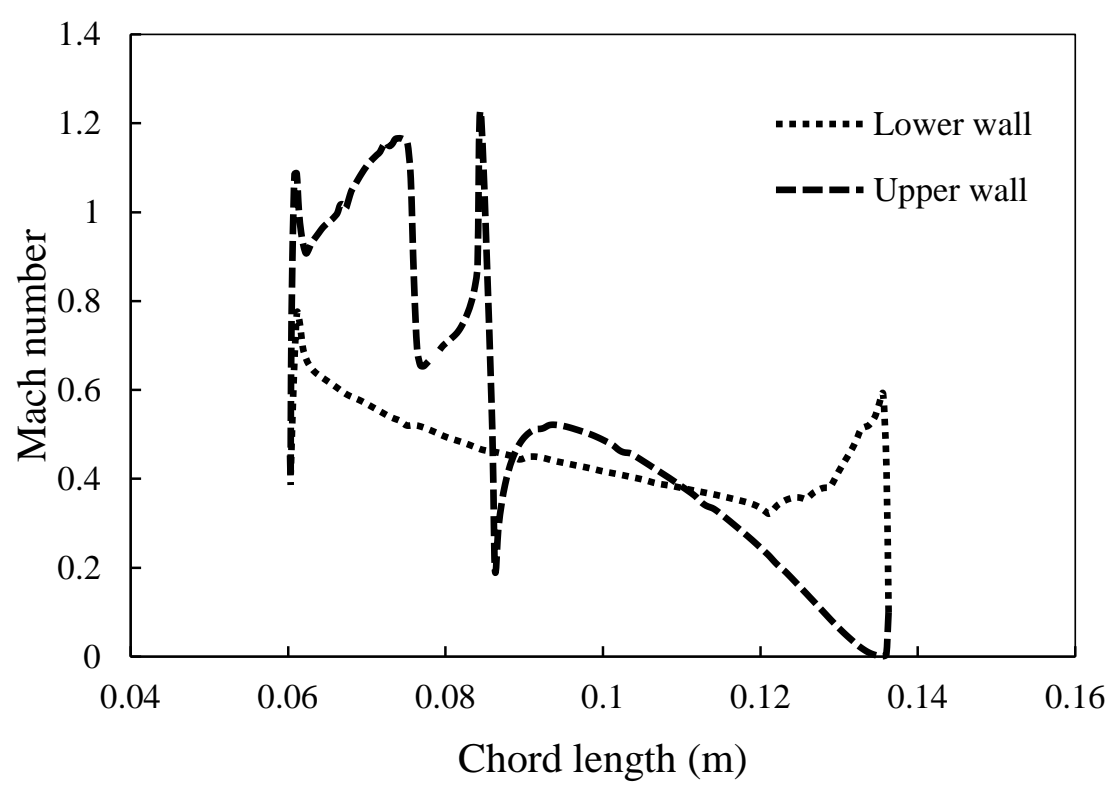

(b) 


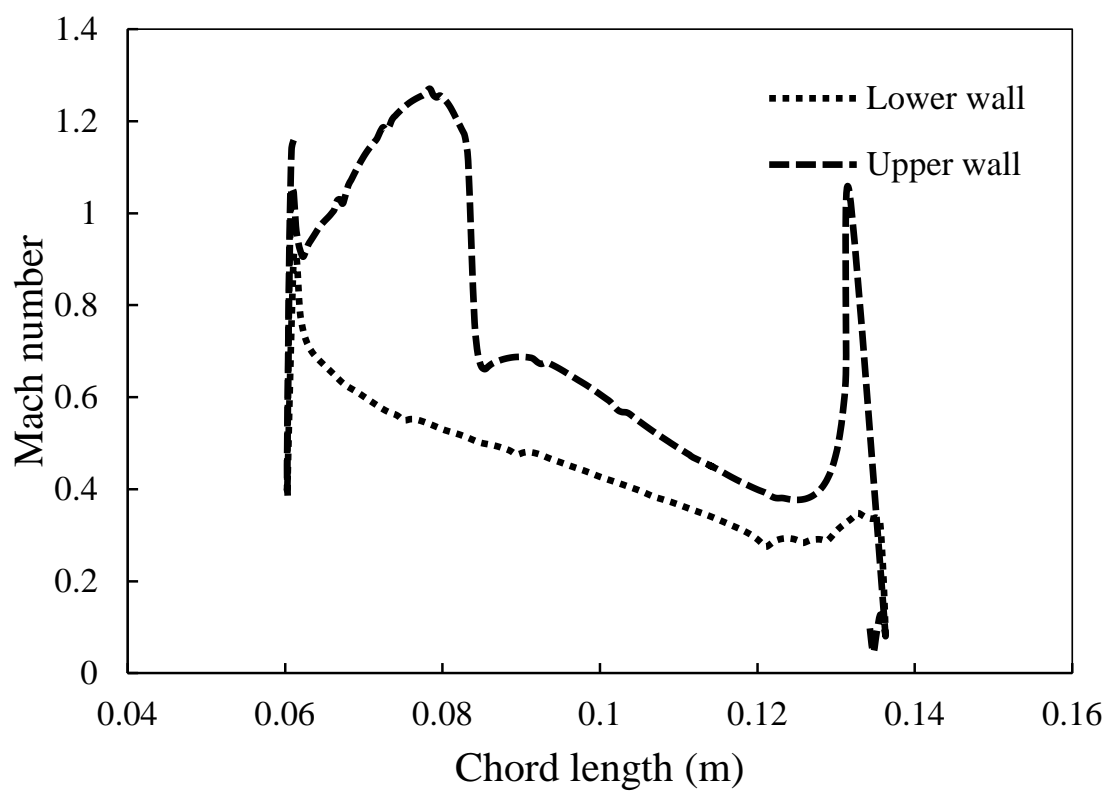

(c)

Figure 10. Changes of Mach number in suction case on the upper and lower walls of the blade for three different cases where the slot was located at (a) $5 \%$, (b) $45 \%$ and (c) $95 \%$ of the blade chord length.

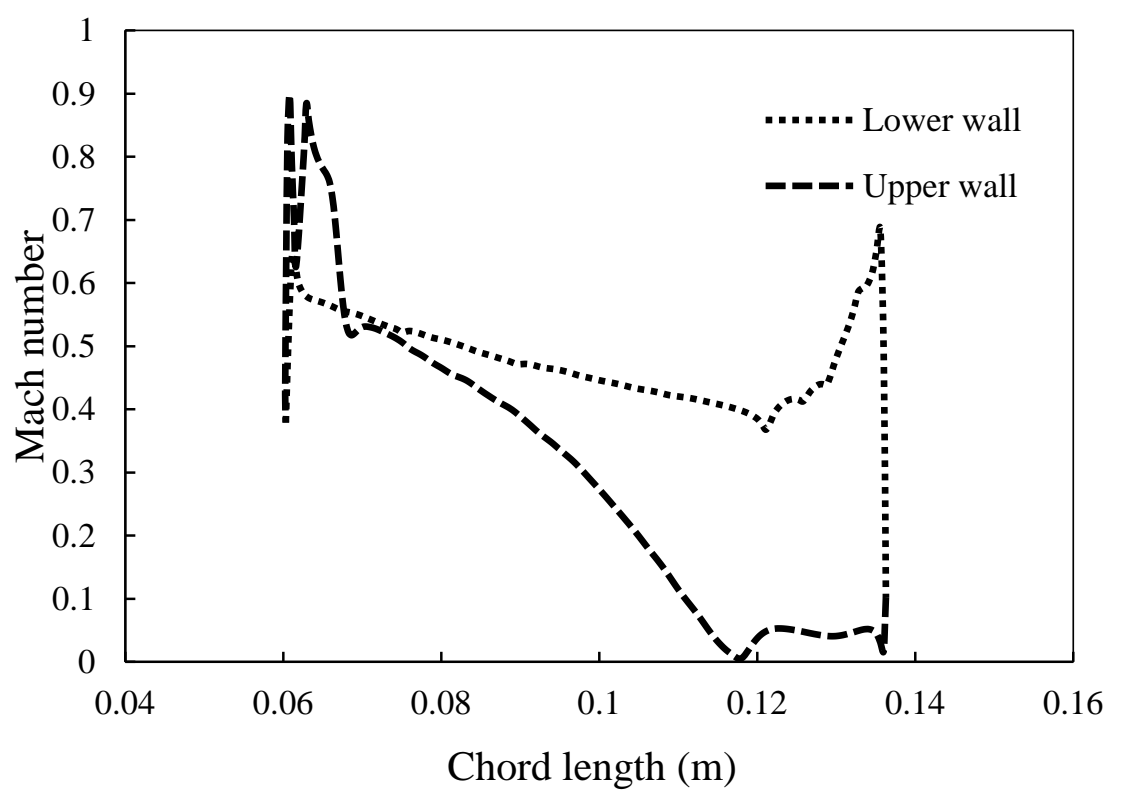

(a) 


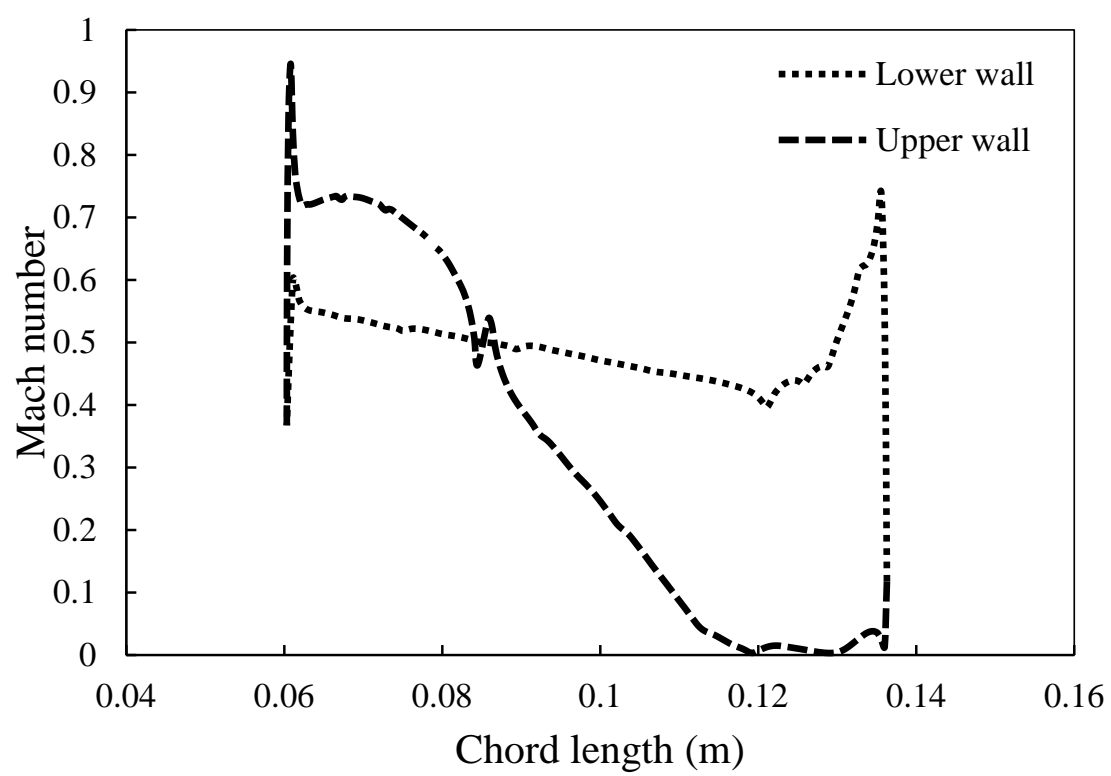

(b)

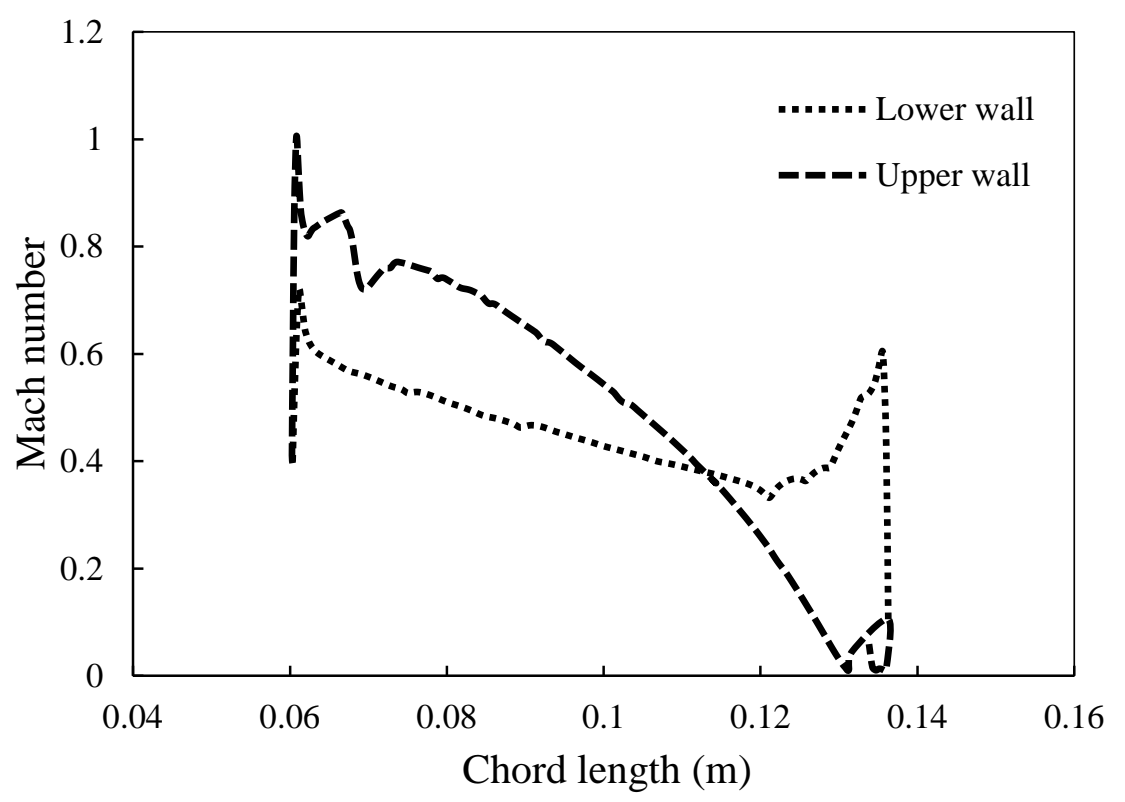

(c)

Figure 11. Changes of Mach number in blowing case on the upper and lower walls of the blade for three different cases where the slot was located at (a) $5 \%$, (b) $45 \%$ and (c) $95 \%$ of the blade chord length.

\section{Changes of Lift and Drag Coefficients}

Figure 12 shows the changes of lift coefficient on the blade based on the slot location for suction and blowing cases. As can be seen for suction case, the lift coefficient increased with a larger slope with respect to the slot location at $5 \%$ to $95 \%$ of the blade chord length as compared to blowing and whatever slot were close to the trailing edge, the lift coefficient had more values than other slot locations. So that the lift coefficient had increased about $45 \%$ at $95 \%$ of chord length for suction compared to $5 \%$ of chord 
length and it had increased about $10 \%$ at $95 \%$ of chord length for blowing compared to $5 \%$ of chord length. Figure 13 indicates the changes of lift coefficient on the blade based on the slot location for suction and blowing. The drag coefficient decreased for both cases which its decreasing slope for suction was greater than blowing. The maximum value of decreasing in drag coefficient was observed for both suction and blowing at $95 \%$ of chord length. The changes of lift and drag coefficients which affected by applying suction and blowing can be considered as changing in the pattern of pressure field around the blade. Suction prevented flow separation by sucking the air with specific ratio into the jet location which had low momentum and eliminated the losses that affected by flow separation. Moreover, it caused to increase the lift coefficient and decrease the drag coefficient.

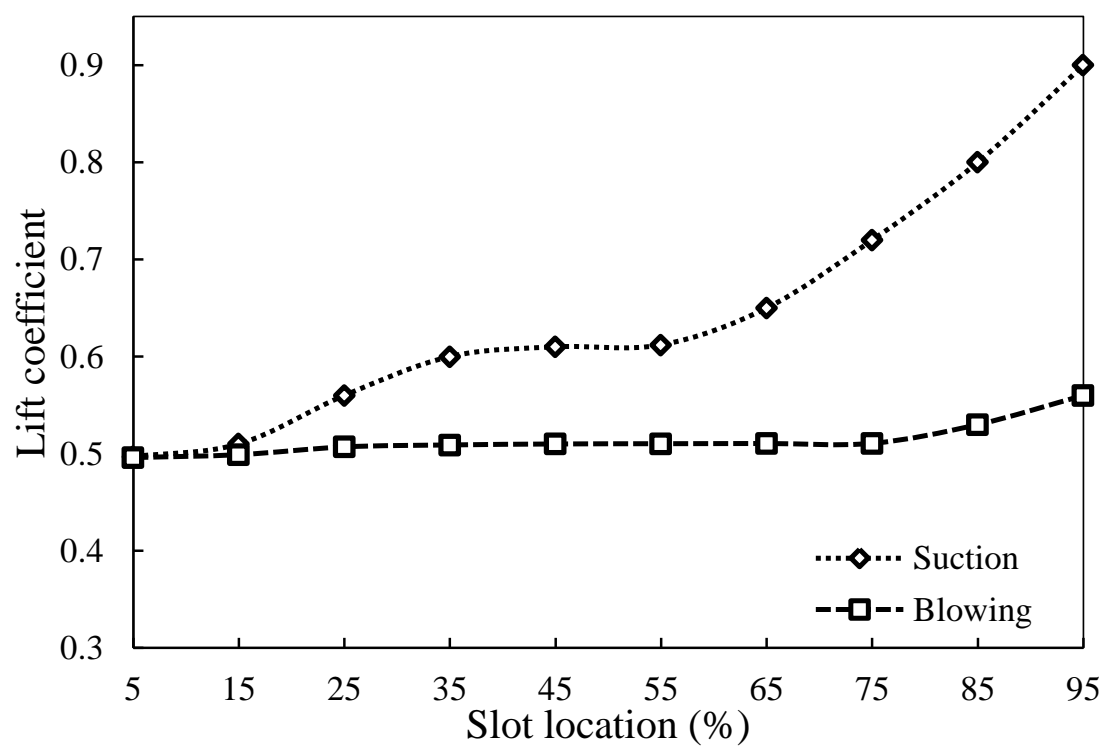

Figure 12. Changes of lift coefficient for suction and blowing cases based on the slot location.

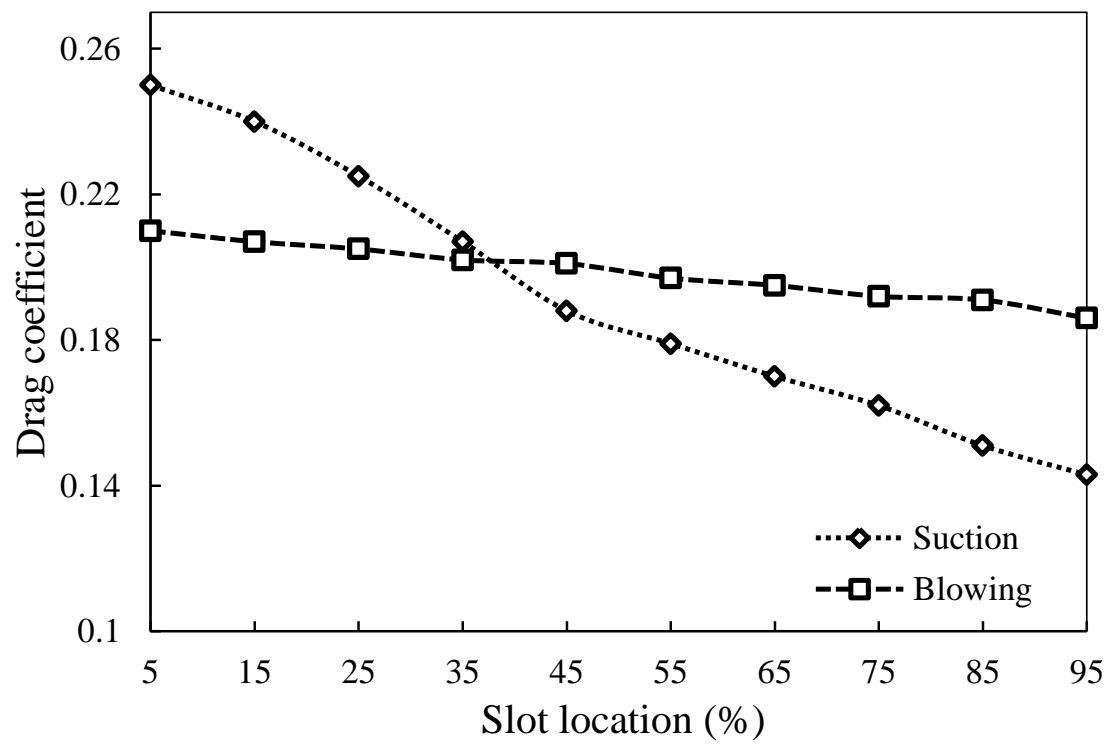

Figure 13. Changes of drag coefficient for suction and blowing cases based on the slot location. 


\section{Changes of Kinetic Energy and Specific Dissipation Rate}

Figure 14 (a) to (c) and Figure 15 (a) to 15 (c) show the changes of kinetic energy on the upper and lower walls of the blade for three different cases where the slot was located at 5\%, 45\% and 95\% of the blade chord length for suction and blowing cases, respectively. The maximum value of kinetic energy can be seen near the leading edge on the upper wall of the blade and this value was decreased with large slope by moving towards the trailing edge and away from the shock zone and finally it increased near the trailing edge. It is important to note that at slot locations, sudden changes had observed which caused by the effect of shock. Also, the value of kinetic energy in the locations near the leading edge was more than other locations of the blade and this value decreased with large slope towards the trailing edge.

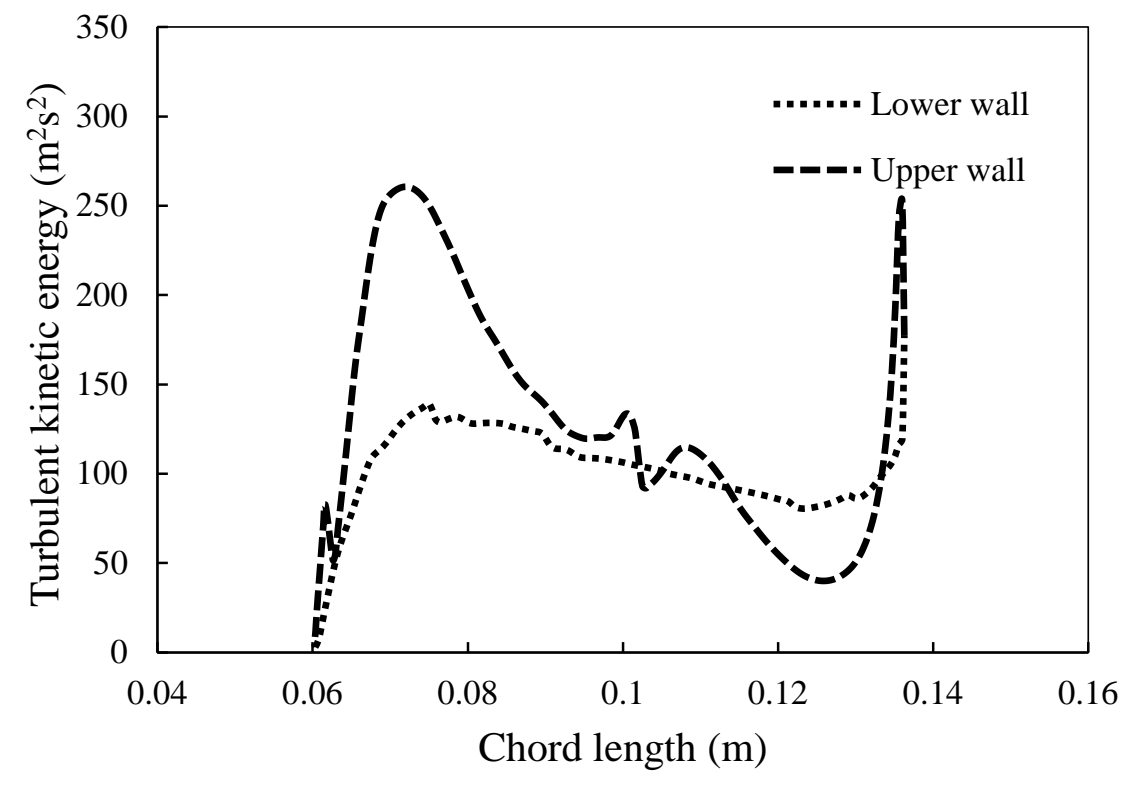

(a)

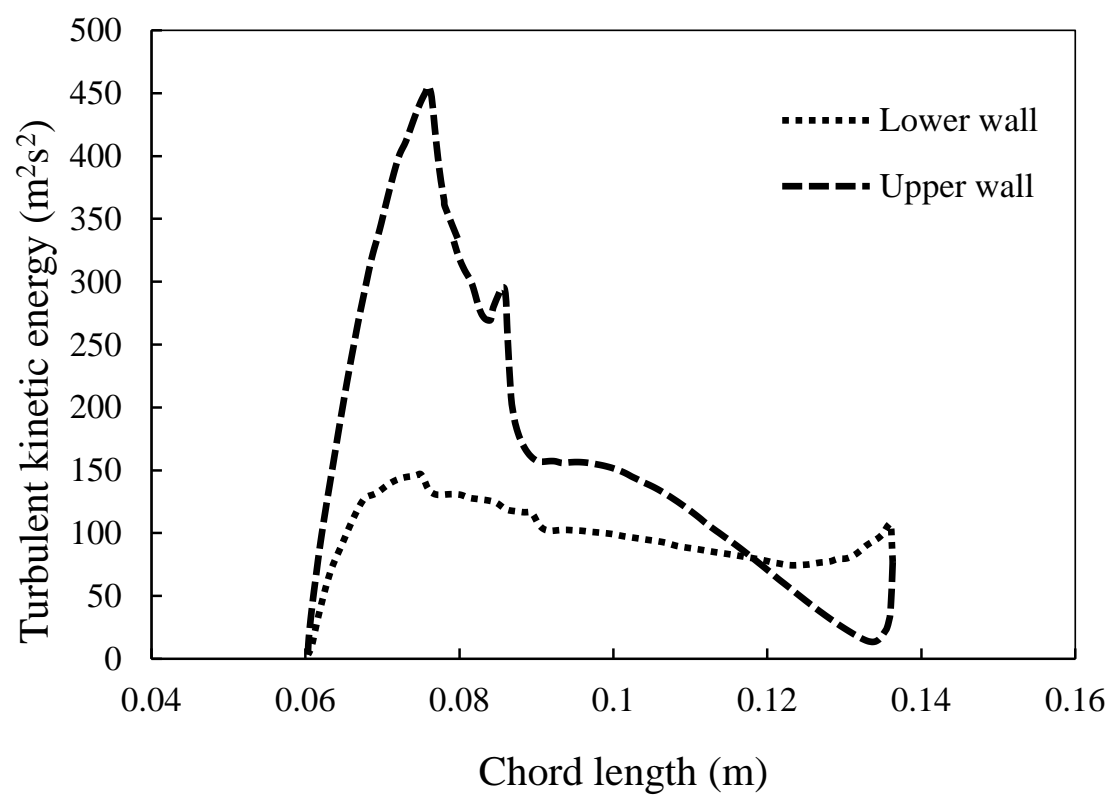

(b) 


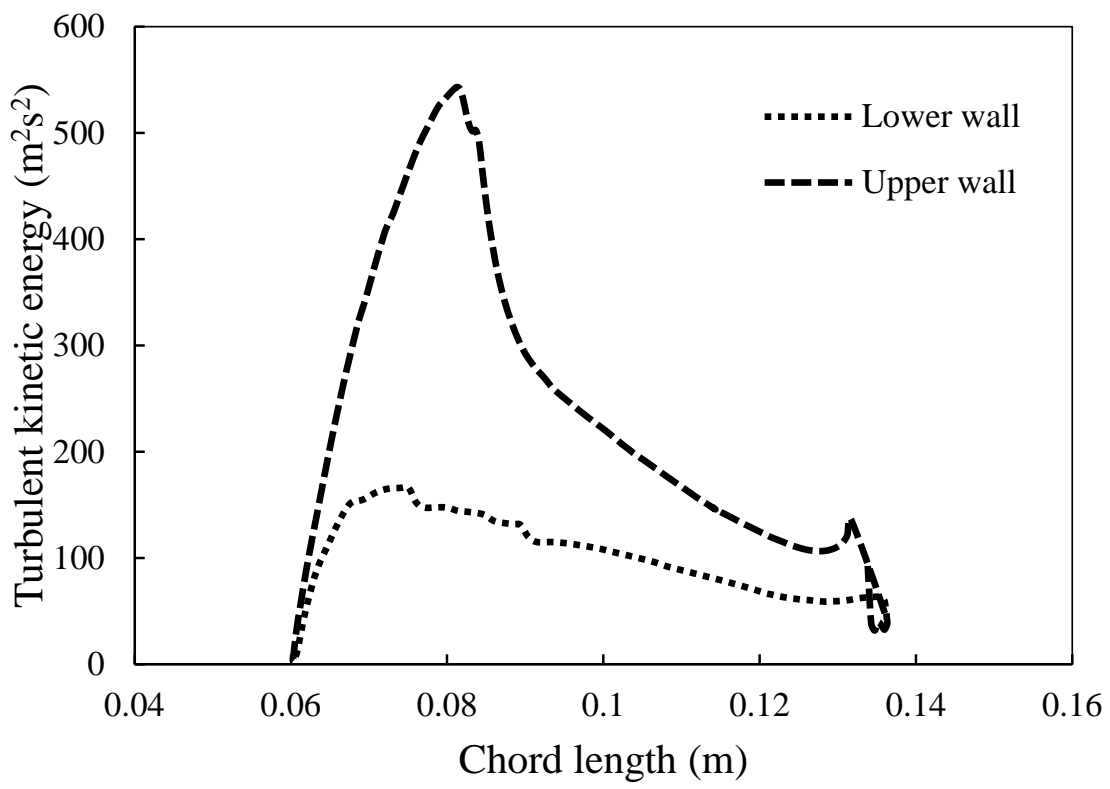

(c)

Figure 14. Changes of kinetic energy in suction case on the upper and lower walls of the blade for three different cases where the slot was located at (a) 5\%, (b) $45 \%$ and (c) $95 \%$ of the blade chord length.

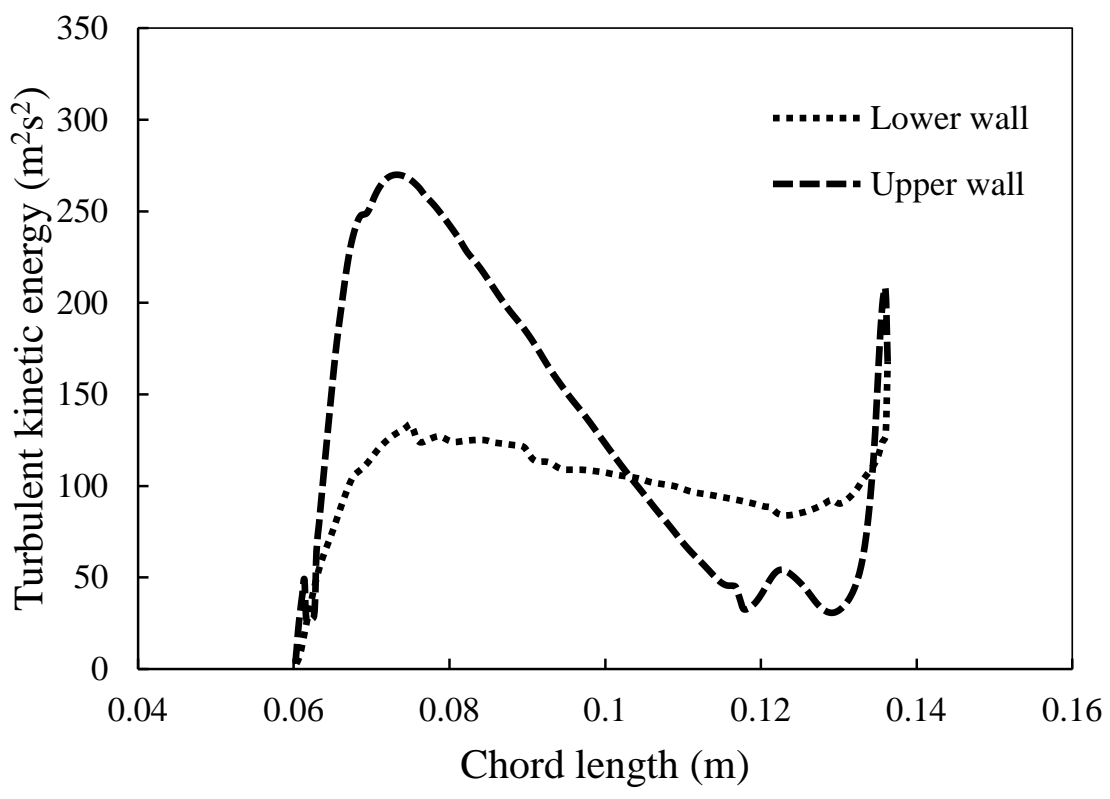

(a) 


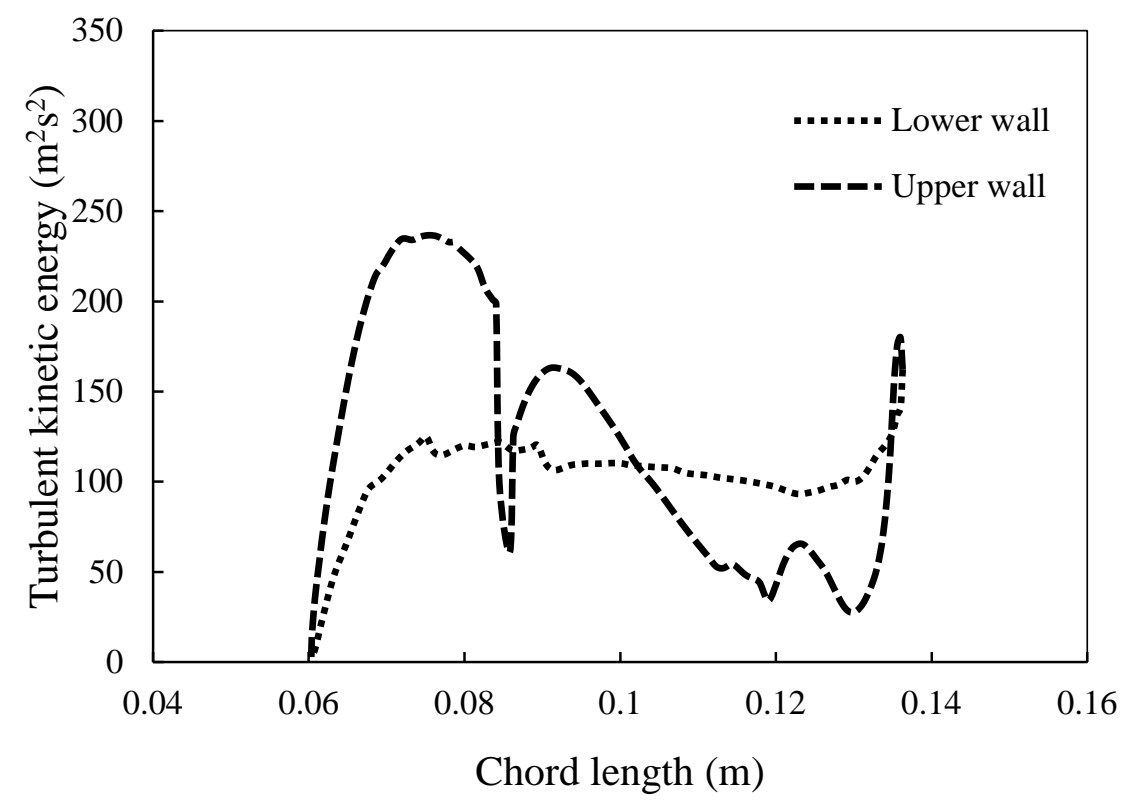

(b)

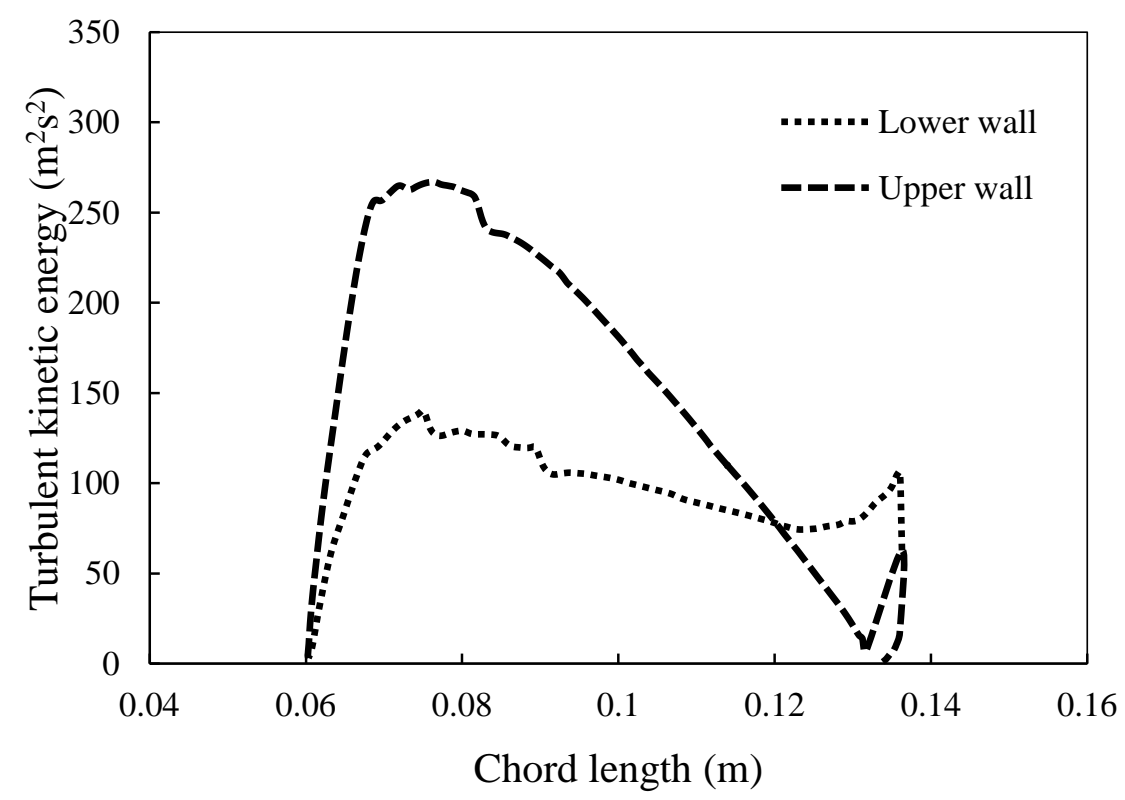

(c)

Figure 15. Changes of kinetic energy in blowing case on the upper and lower walls of the blade for three different cases where the slot was located at (a) 5\%, (b) $45 \%$ and (c) $95 \%$ of the blade chord length.

In compressor cascade, turbulence is more limited to the areas where is near the blade. Thus, turbulence characteristics changes around the blade were used to explain physical phenomena. Figure 16 (a) to (c) and Figure 17 (a) to (c) show the changes of specific dissipation rate on the upper and lower walls of the blade for three different cases where the slot was located at 5\%,45\% and 95\% of the blade chord length for suction and blowing, respectively. As can be seen, specific dissipation rate for upper and lower walls of the blade had oscillations. The maximum value of specific dissipation rate was observed near the leading edge on the upper wall of the blade and 
this value decreased by moving toward the trailing edge and away from the shock zone. The process of turbulence energy production was more affected by shock and its interaction with the boundary layer. In the absence of shocks, it was affected by the areas of maximum Mach number, while the specific dissipation process was more affected by the separation zone and the separated vortices near the blade surface.

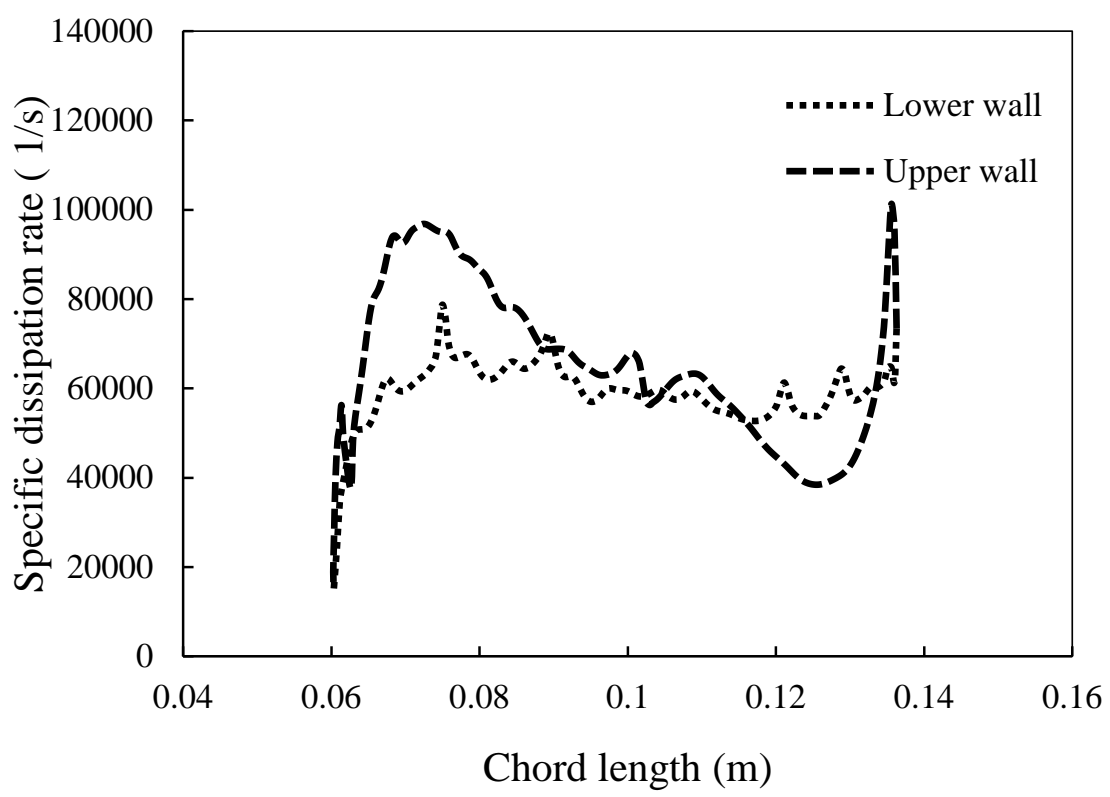

(a)

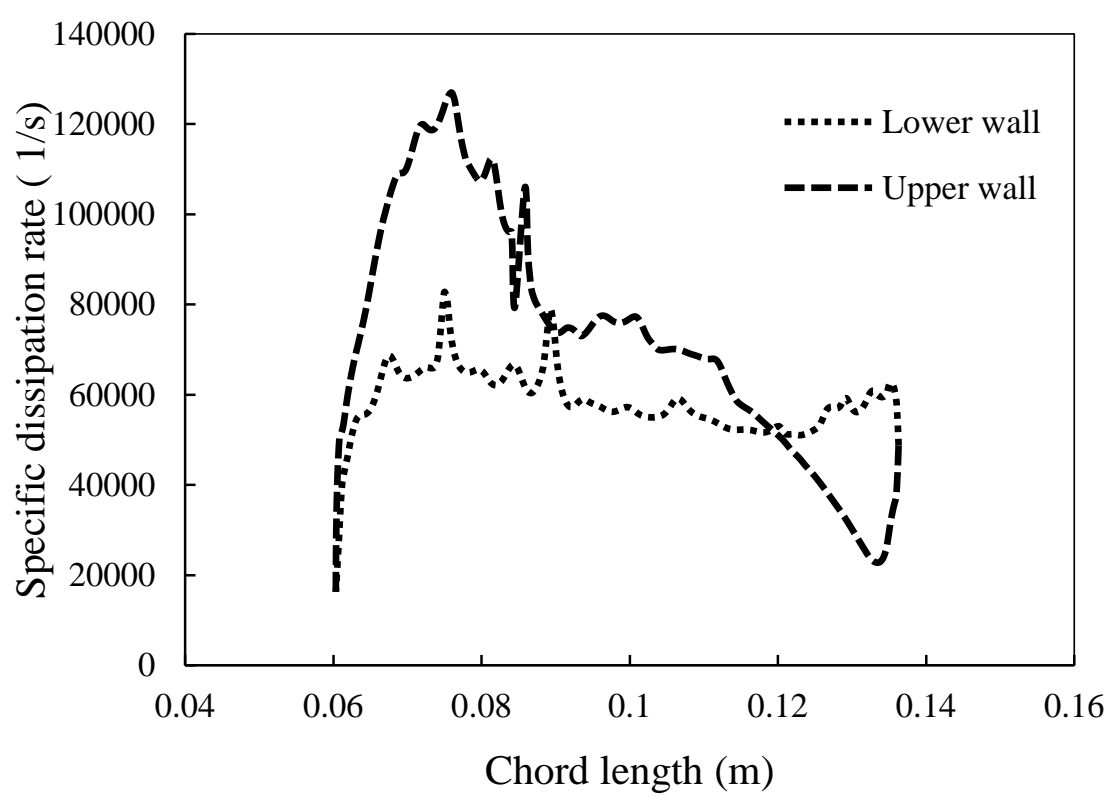

(b) 


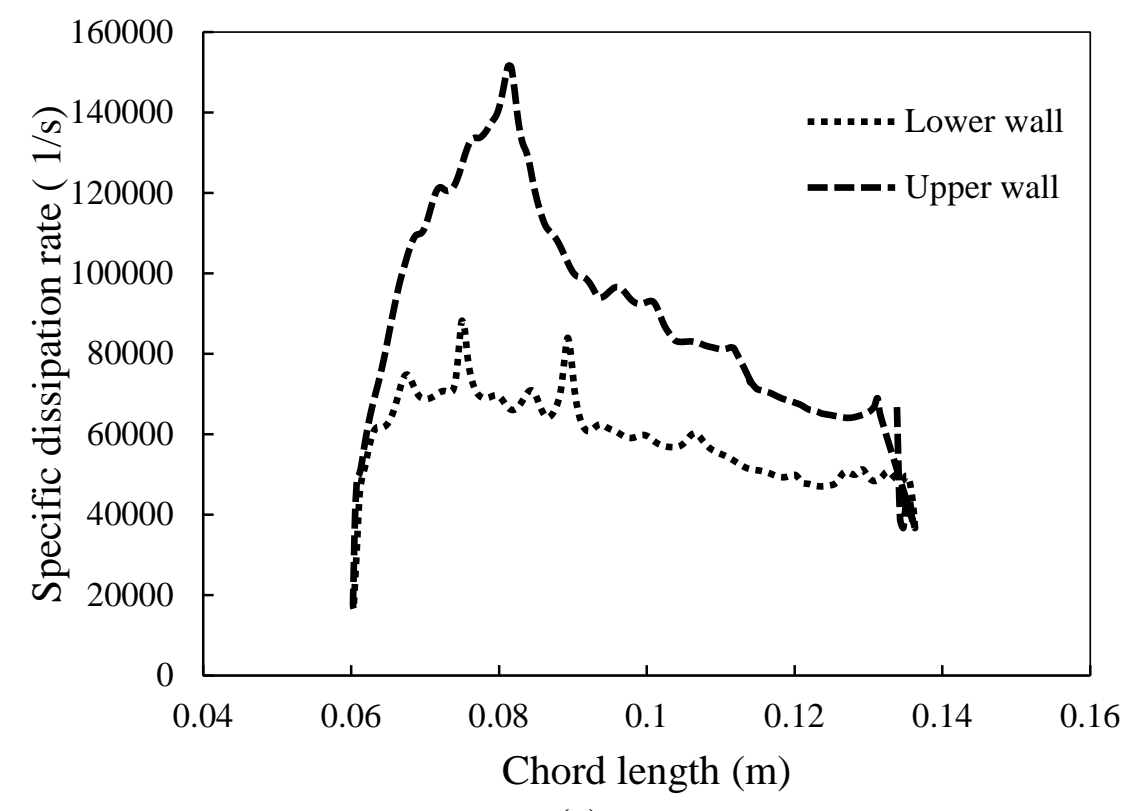

(c)

Figure 16. Changes of specific dissipation rate in suction case on the upper and lower walls of the blade for three different cases where the slot was located at (a) $5 \%$, (b) $45 \%$ and; (c) $95 \%$ of the blade chord length

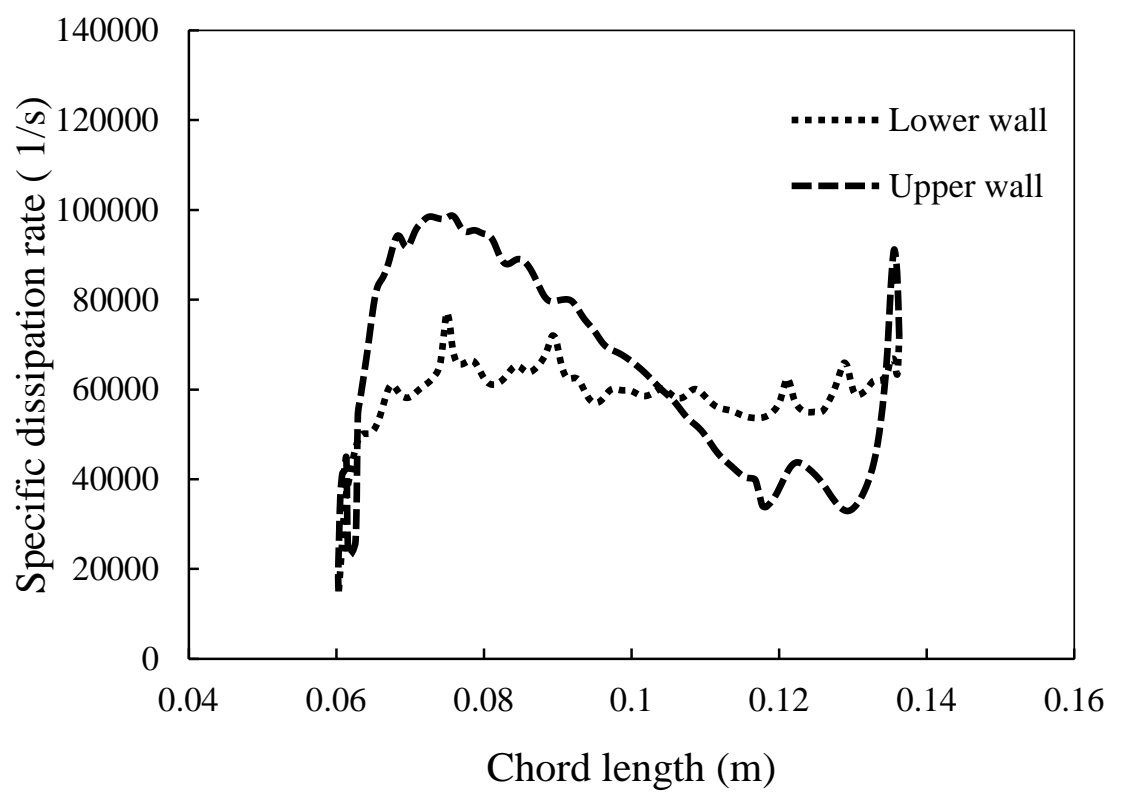

(a) 


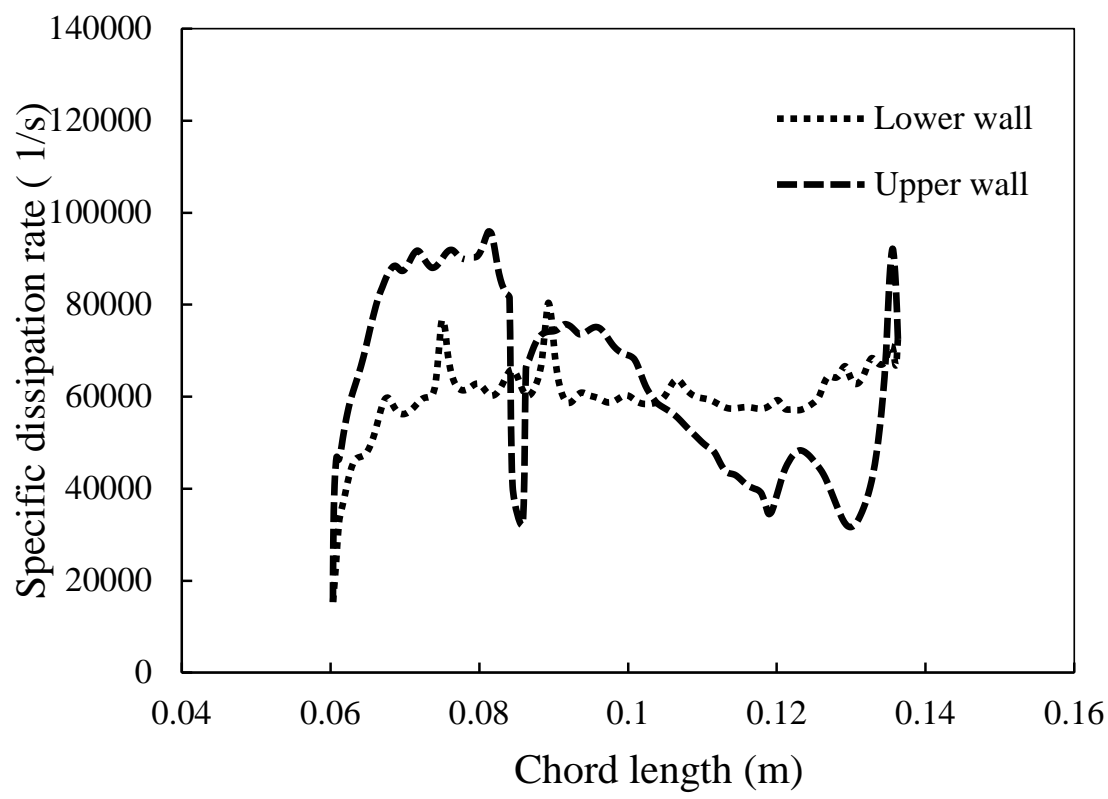

(b)

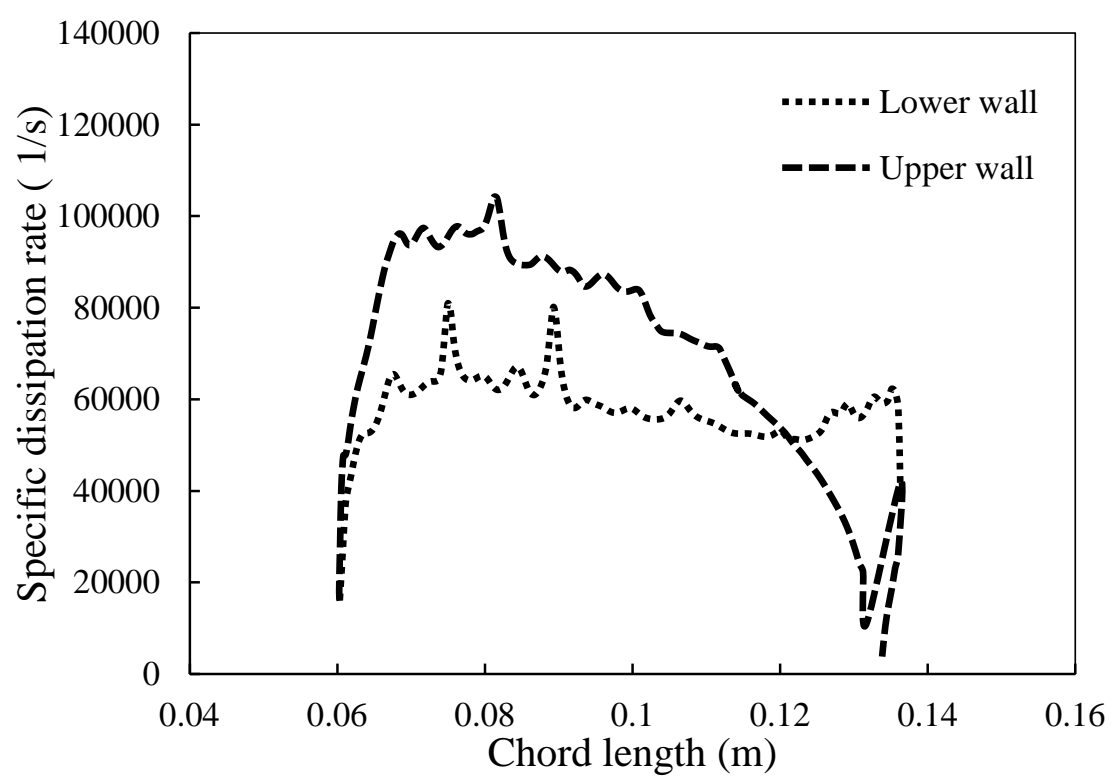

(c)

Figure 17. The changes of specific dissipation rate in blowing case on the upper and lower walls of the blade for three different cases where the slot was located at (a) $5 \%$,

(b) $45 \%$ and (c) $95 \%$ of the blade chord length

\section{CONCLUSION}

In this study, a numerical simulation of flow over the NACA 65-100 compressor cascade which consists of 5 linear blades was conducted to control the boundary layer using both suction and blowing cases, separately. The blade chord length was $80 \mathrm{~mm}$, the distance between the blades was $40 \mathrm{~mm}$ and Reynolds number was $1.4 \times 10^{7}$. The flow was considered as two-dimensional, steady, compressible and turbulent. SST k- $\omega$ turbulence model was used to model the turbulent flow. In order to study the effects of 
suction and blowing on the blade, 10 slots were considered on the upper surface of the blade. The slots were considered at intervals of $5 \%$ to $95 \%$ of the blade chord length. In addition, changes of Mach number, kinetic energy and turbulence dissipation rate were considered. The results showed that the lift coefficient had increased and the drag coefficient had decreased by locating the slot near the trailing edge which the value of these changes in suction case was more than blowing case. Also, the maximum value of kinetic energy was near the leading edge on the upper wall of the blades and this value was reduced with sharp slope at the trailing edge and away from the shock zone. The changes of specific dissipation rate had a similar trend like the changes of kinetic energy but more fluctuations of specific dissipation rate were observed for the upper and lower walls of the blade. Also, the results showed that applying both suction and blowing caused to delay the flow separation, improvement and stability of the flow field around the compressor cascade. Applying suction, especially in the location near the trailing edge was more effective than applying blowing.

\section{REFERENCES}

[1] Feng D, Chen F, Song Y, Chen H, Wang Z. Enhancing aerodynamic performances of highly loaded compressor cascades via air injection. Chinese Journal of Aeronautics 2009; 22(2): 121-128.

[2] Loughery RJ, Horn RA, Tramm PC. Single-stage experimental evaluation of boundary layer blowing and bleed techniques for high lift stator blades. NASA Contractor Report No. CR-54573; 1971.

[3] Kerrebrock JL, Reijnen DP, Ziminsky WS, Smilg LM. Aspirated compressors. In: ASME International Gas Turbine and Aeroengine Congress and Exhibition, American Society of Mechanical Engineers, pp. 110-125; 1997.

[4] Kerrebrock, JL. The prospects for aspirated compressors. AIAA paper; AIAA2000-2472.

[5] Schuler BJ, Kerrebrock JL, Merchant A. (2005) Experimental investigation of a transonic aspirated compressor. Journal of Turbomachinery 2005; 127(2): 340348.

[6] Fottner L. Theoretical and experimental investigations on aerodynamically highly-loaded compressor bladings with boundary layer control. In: 4th International Symposium on Air Breathing Engines, pp. 7032-7041; 1980.

[7] Merchant A. Aerodynamic design and performance of aspirated airfoils. In: ASME Turbo Expo: Power for Land, Sea, and Air, American Society of Mechanical Engineers, pp. 421-431; 2002.

[8] Qiang X, Wang S, Lin W, Wang Z. A New Design Concept of Highly-Loaded Axial Flow Compressor by Applying Boundary Layer Suction and 3D Blade Technique. In: ASME International Mechanical Engineering Congress and Exposition, American Society of Mechanical Engineers, pp. 81-88; 2008.

[9] Wang S, Qiang X, Lin W, Feng G, Wang Z. Highly-loaded low-reaction boundary layer suction axial flow compressor. In: ASME Turbo Expo: Power for Land, Sea, and Air, American Society of Mechanical Engineers, pp. 405412; 2007.

[10] Niu YC, Zhu JQ, Nie CQ, Ge ZW. Experimental investigations of aerodynamics performance of aspirate subsonic compressor cascade. Journal of Aerospace Power 2008; 23(3): 483-489. 
[11] Zheng XQ, Zhou XB, Zhou S. Investigation on a type of flow control to weaken unsteady separated flows by unsteady excitation in axial flow compressors. Journal of Turbomachinery 2005; 127(3): 489-496.

[12] Song Y, Chen F, Yang J, Wang Z. A numerical investigation of boundary layer suction in compound lean compressor cascades. Journal of Turbomachinery 2006; 128(2): 357-366.

[13] Yanping S, Fu C, Guijie ZH, Kaiying C, Zhongqi W. Numerical investigation of boundary layer suction in compressor cascade with large turning angles. Journal of Aerospace Power 2005; 20(4): 561-566.

[14] Song Y, Chen F, Zhao G, Chen K, Wang Z. Effects of suction slot geometries on the performance of compressor cascade. Journal of Engineering Thermophysics 2005; 26(5): 761-774.

[15] Chen F, Song Y, Chen H, Wang Z. Effects of boundary layer suction on the performance of compressor cascades. In: ASME Turbo Expo: Power for Land, Sea, and Air, American Society of Mechanical Engineers, pp. 91-100; 2006.

[16] Chen F, Chen H L, Song Y P, Wang Z Q. Aerodynamic performance of highturning curved compressor cascade with boundary layer suction. Journal of Harbin Institute of Technology-English Edition 2007; 14(3): 341-355.

[17] Chen F, Song Y, Zhao G, Liu J, Wang Z. Effects of boundary layer suction on the performance of compressor cascade with different solidities. Journal of Engineering Thermophysics 2005; 26(2): 211-215.

[18] Nerger D, Saathoff H, Radespiel R, Gümmer V, Clemen C. Experimental investigation of endwall and suction side blowing in a highly loaded compressor stator cascade. Journal of Turbomachinery 2012; 134(2): 230-248.

[19] Guo S, Lu H, Chen F, Wu C. Vortex control and aerodynamic performance improvement of a highly loaded compressor cascade via inlet boundary layer suction. Experiments in fluids 2013; 54(7): 1570-1588.

[20] Ding J, Chen S, Xu H, Sun S, Wang S. Control of flow separations in compressor cascade by boundary layer suction holes in suction surface. In: ASME Turbo Expo: Turbine Technical Conference and Exposition, American Society of Mechanical Engineers, pp. 35-52; 2013.

[21] Sarimurat MN, Dang TQ. An analytical model for boundary layer control via steady blowing and its application to NACA-65-410 cascade. Journal of Turbomachinery 2014; 136(6): 220-236.

[22] Turek, T. Flow field in the compressor blade cascade NACA 65-100, STC Conference, Prague, pp. 40-65; 2010.

[23] Wang H, Zhang B, Qiu Q, Xu X. Flow control on the NREL S809 wind turbine airfoil using vortex generators. Energy 2017; 118(3): 1210-1221.

[24] Fluent A. 14.5 theory guide. Canonsburg, PA, USA, ANSYS Inc; 2012.

[25] Taher A, Kanfoudi H, Ennouri M, Zgolli R. Numerical Study of Unsteady Cavitating Flows around a Hydrofoil. Journal of Applied Fluid Mechanics 2017; 10(1): 55-71.

[26] Cao Z, Liu B, Zhang T. Control of separations in a highly loaded diffusion cascade by tailored boundary layer suction. Proceedings of the Institution of Mechanical Engineers, Part C: Journal of Mechanical Engineering Science 2014; 228(8): 1363-1374. 